\title{
Costs and benefits of climate change in Switzerland
}

\author{
Frank Vöhringer ${ }^{\mathrm{a}, \mathrm{b}, \mathrm{d}, *}$, Marc Vielle ${ }^{\mathrm{a}}$, Philippe Thalmann ${ }^{\mathrm{a}}$, Anita Frehner ${ }^{\mathrm{a}, \mathrm{e}}$, \\ Wolfgang Knoke ${ }^{\mathrm{a}, \mathrm{f}}$, Dario Stocker ${ }^{\mathrm{a}, \mathrm{c}, \mathrm{d}}$, Boris Thurm ${ }^{\mathrm{a}}$ \\ ${ }^{a}$ LEURE Laboratory, Swiss Federal Institute of Technology at Lausanne (EPFL), CH-1015 \\ Lausanne, Switzerland. \\ ${ }^{b}$ Econability, Fischermatt 12, CH-3127 Mühlethurnen, Switzerland. \\ ${ }^{c}$ Oeschger Centre for Climate Change Research, University of Bern, Falkenplatz 16, CH-3012 \\ Bern, Switzerland. \\ ${ }^{d}$ Faculty of Business, Economics and Social Sciences, University of Bern, Schanzeneckstrasse 1, \\ CH-3001 Bern, Switzerland. \\ ${ }^{e}$ FiBL, Departement für Sozioökonomie, Ackerstrasse 113, CH-5070 Frick, Switzerland. \\ ${ }^{f}$ Wolfgang Knoke Forschungsagentur, Unterster Zwerchweg 14, D-60599 Frankfurt, Germany.
}

\begin{abstract}
Understanding the economic magnitude of climate change impacts is a prerequisite for developing adequate adaptation strategies. In Switzerland, despite new climate scenarios and impact studies, only few impacts have been monetized. Our objective is to assess costs and opportunities of climate change for Switzerland by 2060 , while enhancing the assessment methods. Using inputs from bottom-up impact studies, we simulate the economic consequences of climate scenarios in a CGE framework. We cover health, buildings/infrastructure, energy, water, agriculture, tourism, the spill-overs to other sectors, and international effects. Due to data constraints, significant impacts have not been quantified, e.g. for heat waves and droughts more extreme than the 2060 average climate. For the considered impacts, welfare decreases by $0.37 \%$ to $1.37 \%$ in 2060 relative to a reference without climate change. Higher summer temperatures increase mortality and decrease productivity. Contrariwise, tourism benefits from extended summer seasons. Regarding energy, increased demand for cooling is overcompensated by savings in heating.
\end{abstract}

Keywords: Climate change impacts, Adaptation, Switzerland, Computable general equilibrium model

\footnotetext{
${ }^{*}$ Corresponding author. Tel.: +4131 8120000 .

Email address: frank.voehringer@epfl.ch (Frank Vöhringer)
} 


\title{
Costs and benefits of climate change in Switzerland
}

\begin{abstract}
Understanding the economic magnitude of climate change impacts is a prerequisite for developing adequate adaptation strategies. In Switzerland, despite new climate scenarios and impact studies, only few impacts have been monetized. Our objective is to assess costs and opportunities of climate change for Switzerland by 2060, while enhancing the assessment methods. Using inputs from bottom-up impact studies, we simulate the economic consequences of climate scenarios in a CGE framework. We cover health, buildings/infrastructure, energy, water, agriculture, tourism, the spill-overs to other sectors, and international effects. Due to data constraints, significant impacts have not been quantified, e.g. for heat waves and droughts more extreme than the 2060 average climate. For the considered impacts, welfare decreases by $0.37 \%$ to $1.37 \%$ in 2060 relative to a reference without climate change. Higher summer temperatures increase mortality and decrease productivity. Contrariwise, tourism benefits from extended summer seasons. Regarding energy, increased demand for cooling is overcompensated by savings in heating.

Keywords: Climate change impacts, Adaptation, Switzerland, Computable general equilibrium model
\end{abstract}

\section{Introduction}

For Switzerland, as for other continental regions, climatologists expect a temperature increase much higher than the global average. Even up to 2011, Switzerland has experienced an increase by $1.7^{\circ} \mathrm{C}$ since the beginning of institutionalized temperature measurements in 1864, while the average on-land warming in the northern hemisphere amounted to $1.1^{\circ} \mathrm{C}$ (Perroud and Bader, 2013). Under these circumstances, it is necessary to inquire about climatic effects in Switzerland and their economic magnitude. Understanding these effects is a prerequisite for developing adequate adaptation strategies, with the objective to reduce damages and to reap opportunities of climate change $(\mathrm{CC})$. Despite this, there has been little research that would include attempts for monetization over a long period of time $\mathrm{H}^{1}$ One of the reasons is the complexity and heterogeneity of the subject: Many sectors are involved in very different ways, requiring different types of analyses.

\footnotetext{
${ }^{1}$ See the literature overviews in Sections 2 and 3.1
} 
This paper summarizes the results of a research program on the possible costs and opportunities of climate change for Switzerland by 2060. The main goal of this program is to bundle, update and complete earlier assessments with a view to producing a full picture of the economic consequences of CC in Switzerland by 2060. This evaluation is performed with a computable general equilibrium (CGE) model, perturbated by a selected number of CC hazards which, based on other studies or our earlier research, are expected to be important in terms of impacts and quantifiable in terms of data availability. Indeed, we cover the majority of significant trend-related hazards. Insufficient data prevent us from simulating the impacts of weather extremes, which are known to be important causes of climate damage.

In order to keep the impacts of the many $\mathrm{CC}$ hazards traceable, we simulate them separately in six domains: health, buildings and infrastructure, energy, water management, agriculture, and tourism. The simulations include the spill-over effects from these domains to other sectors. In addition, we simulate all of the modeled hazards jointly to determine interaction effects.

The remainder of the paper is organized as follows. Section 2 briefly details the existing assessments of expected impacts of CC in Switzerland. Section 3 describes the methodology used in this paper. In a section 4, we explain how a selected number of CC hazards can affect the Swiss economy and evaluate for each of them the resulting economic impacts. Section 5 provides an overall view of CC impacts in Switzerland and a ranking of the sectoral impacts. The last section concludes.

\section{Earlier economic assessments of climate change impacts in Switzerland}

Although Meier (1998) made a first crude attempt to monetize the possible impacts of CC in Switzerland, it was not before 2007 that the first considerable and encompassing estimation of the costs of CC for the Swiss economy was conducted by Ecoplan and Sigmaplan (Ecoplan/Sigmaplan, 2007). This study focused on CC occurring in Switzerland, while another study (INFRAS et al., 2007) estimated the impacts on Switzerland of CC hazards occurring in the rest of the world. These were the last all-encompassing economic assessments to date of the possible consequences of CC for Switzerland. Ecoplan/Sigmaplan (2007) estimated that there would be hardly any impacts by 2030 and moderate impacts until $2050(0.15 \%$ of GDP), but that they would grow substantially until the end of the century, to reach $0.5 \%$ of GDP with a large margin of uncertainty, from $0.15 \%$ to $1.6 \%$. The 
authors attributed $40 \%$ of that uncertainty to that of the climate scenarios and $60 \%$ to the translation of these scenarios into economic losses.

Since the 2007 studies, new climate scenarios were developed (CH2011, 2011) and new impact studies were published. Swiss Confederation (2012) was a first global assessment of the challenges facing all policy fields of Switzerland due to $\mathrm{CC}$ hazards. The assessment of the impacts is qualitative, based on published results and expert statements. The report identified priorities for action. It was elaborated by ten Swiss federal offices and other units and designed as the first part of the national adaptation strategy. The CH2014-Impacts report (CH2014Impacts, 2014) presents research advancements for various sectors individually, such as tourism, agriculture and energy demand. Its authors translated the climate scenarios CH2011 into quantitative hazards for the cryosphere, hydrology, biodiversity, forests, agriculture, energy use and health. Very few of these hazards are translated into monetized impacts. Comprehensive economic assessments of risks induced by $\mathrm{CC}$ were completed in a series of 8 cantons that were selected to be each representative of a main geographical region of Switzerland. ${ }^{2}$

\section{Methodology}

Different approaches can be taken to analyze the impacts of $\mathrm{CC}$ in an economic setting, which all have their advantages and shortcomings. Approaches can be descriptive, semi-quantitative (e.g. multi-criteria analysis), or quantitative (bottom-up, partial equilibrium, general equilibrium, macroeconomic / econometric models).

The cantonal case studies indicate that $\mathrm{CC}$ impacts should not just be considered individually, but also in their interactions. A striking result of these studies is that for individual sectors, socio-economic changes and their uncertainties are often more important than climate hazards and their uncertainties. These considerations call for an integrated assessment of CC impacts, combining the predicted climate modifications and the expected socio-economic trends into a coherent model of the Swiss economy.

\footnotetext{
${ }^{2}$ The reports for these seven cantons are available: Aargau, Basel-Stadt, Fribourg, Geneva, Graubünden, Ticino and Uri. They are: Ernst Basler + Partner et al. (2013); INFRAS and Egli Engineering (2014a b); INFRAS et al. (2015); Bergwelten 21 and GRF Davos (2015); IFEC et al. (2016); Ernst Basler and Partner/CSD Ingenieurs (2015).
} 


\subsection{Literature review}

Recently, Tol (2018) reviewed estimates of the total economic impacts of CC. He distinguished three methods to analyse the economic effects of CC.

Most studies use the so-called enumerative method, where several physical effects of CC are multiplied by a price (i.e. a cost) and then summed. The result is an estimate of the direct cost, which doesn't take into account any interactions between sectors and economic markets.

Some other estimates adopt a statistical approach, linking economic variables (through statistical methods) to climate variables and then computing the impact of deviations on the climate variables. For example, some researchers have chosen to estimate economy-wide impacts by regressing GDP or GDP growth per capita for panels of countries on climatic variables such as average temperature or extreme events in addition to other standard determinants of growth, e.g. (Burke et al., 2015; Du et al., 2017; Zhao et al., 2018).

Finally, a growing number of studies use CGE models. They take physical effects of $\mathrm{CC}$ obtained from natural sciences (like in the enumerative method) and integrate them into the CGE model by shocking some associated variables. CGE models are based on neo-classical economic theory and model the whole economy and hence take into account feedback between the different economic agents. They have been used widely for the analysis of $\mathrm{CC}$ mitigation policies, and more recently are involved in the estimation of economic effects of CC.

An early study that used a CGE model to estimate economy-wide impacts of climate change is that of Jorgenson et al. (2004), who estimated the costs of climate change for the USA for a range of climate scenarios up to 2100 . The climate effects are captured through percentage changes in unit production costs (or total factor productivity) for the agriculture, forestry, energy and water sectors. Sea level rise is expressed as a diversion of investment from other uses and the health and mortality impacts are expressed as reductions in the numbers of consumers and potential labor supply. The impacts for other sectors such as tourism are not taken into account, nor trade effects from CC impacts in other parts of the world. Abler et al. (2009) used a dynamic CGE calibrated to the State of Pennsylvania, the USA and world economies to assess statewide market impacts of CC. They represented 32 sectors of which 16 were defined as climate sensitive, of which 13 represent food and wood production and processing and the other water supply and energy demand. Sectoral estimates of CC impacts are used to modify the productivity of the concerned sectors. In this study, trade with the rest of the USA and the world plays some role. However, the direct impacts of CC on some sectors such as tourism and on health and labor productivity are not represented. A third 
assessment of CC impacts in the USA based on a CGE was obtained by the large team of Houser et al. (2015). They examine first CC impacts in a range of areas, before aggregating them to macroeconomic effects up to 2100 . The CC impacts on agriculture are represented as a percentage decrease in total factor productivity. Health effects are captured through changes in the size and composition of the population and in labor supply. Impacts on energy demand are represented by proportional changes in expenditure. The rising sea level reduces exposed capital stocks. Impacts on tourism and international trade are ignored in the simulations.

Studies taking into account an international perspective involve world multisector CGE models where several regions are represented. Ciscar et al. (2012) used the GEM-E3 model to estimate the impacts of CC in Europe on agriculture, river floods, coastal systems and tourism. They found that the EU welfare loss ranges between $0.2 \%$ to $1 \%$ depending on the climate scenario. OECD (2015) extended the analysis by adding impacts on health and energy demand and by considering not only Europe but also 22 other regions. They concluded that net economic consequences are projected to be negative in 23 of the 25 regions. They are especially large in Africa and Asia. Finally, Roson and Sartori (2016) aimed at systematizing the analysis and estimated for all 140 countries and regions of the GTAP model the impacts of CC. Their findings confirm that the negative effects of climate change will be mainly borne by developing countries, located in tropical regions.

\subsection{A general equilibrium framework}

Adding to this stream of literature, we choose to investigate the $\mathrm{CC}$ costs and benefits with the help of a general equilibrium framework and present options to model CC impacts and adaptation within that framework. Based on an analysis of existing research gaps, we opt for an approach which builds up information and model inputs sector by sector, such that, at least in principle, the analysis integrates information from all kinds of studies. Of course, this is hardly possibly without any consistency issues, although we build our approach as much as possible on sources which use the same or similar scenarios as well as compatible methods. The need to combine sources with very different methodological backgrounds reflects the state of affairs in the research on the impacts of CC: detailed sector by sector approaches to determine economic impacts of $\mathrm{CC}$ are still relatively new (e.g. Dowling, 2013; Faust et al., 2015; Gonseth et al., 2017; Gonseth and Vielle, 2017; Holzkämper et al., 2015; Wiebe et al., 2015). At the same time, the field involves many sectors, individual impacts, determinants and uncertainties. As a 
consequence, the research field will remain lively and challenging for many years to come.

We build on the existing literature, but take things further with a more comprehensive quantitative assessment. We use a general equilibrium approach, because inter-sectoral dependencies, feedbacks within the economy, and international impacts are crucial for the analysis of impacts of CC in Switzerland. Indeed, due to the fact that sectors compete for factors of production and that the outputs of some sectors might serve as intermediate inputs for other sectors, the impact of CC on one sector of the economy might have noticeable effects on related sectors. Also, domestic CC impacts could be small for some sectors. However, due to international trade, significant impacts of $\mathrm{CC}$ in other countries could be transmitted to Switzerland and have non-negligible effects on the economy.

\subsection{The GEMINI-E3 model}

GEMINI-E3 $3^{3}$ is a multi-country, multi-sector, recursive CGE model comparable to many other CGE models as e.g. EPPA (Chen et al., 2017) and OECD EnvLinkage (Château et al., 2014) built and implemented by other modeling teams and institutions, and shares the same long experience in the design of this class of economic models. The standard model is based on the assumption of total flexibility in all markets, both the macroeconomic markets such as the capital and the exchange markets (with the associated prices being the real rate of interest and the real exchange rate, which are endogenous), and the microeconomic or sector markets (goods, factors of production). The model is built on the Swiss input-output table (Nathani et al., 2011) and the GTAP database version 8 (Badri Narayanan et al., 2012) for the other countries.

For each sector, the model computes the demand for its production on the basis of household consumption, government consumption, exports, investment, and intermediate uses. Total demand is then divided between domestic production and imports, using the Armington assumption (Armington, 1969). Under this convention a domestic product is distinguished from an imported product of the same industry. All goods are traded in world markets and bilateral trade flows are also represented through the Armington assumption. Production technologies are described by nested constant elasticity of substitution (CES) functions.

Time periods are linked through endogenous real interest rates that equate savings and investment. Capital is not mobile across regions. National and regional

\footnotetext{
${ }^{3}$ All information about the model can be found at http://gemini-e3.epfl.ch/, including its complete description.
} 
models are linked by endogenous real exchange rates resulting from constraints on foreign trade deficits or surpluses.

The sectoral structure of the model has been extended in order to assess the economic impact of CC hazards on particularly vulnerable sectors, such as tourism, agriculture and water distribution. We represent 21 sectors: Appendix Apresents this classification. With regard to the regions represented by this model, we use an aggregated version of GEMINI-E3 that describes six countries/regions: Switzerland $(\mathrm{CH})$, the European Union (EU), the United States of America (USA), other developed countries (OECD), BRIC (Brazil, Russia, India and China), and the rest of the world (ROW).

\subsection{Climate scenarios}

For the sake of comparability, we base our analysis on the three scenarios used in CH2011 (2011) and CH2014-Impacts (2014): A1B, A2 and RCP3PD. Climate projections for the A1B scenario are based on a combination of global and regional circulation models used in the ENSEMBLES project (van der Linden and Mitchell, 2009), while A2 and RCP3PD data were obtained using a pattern scaling method ( $\overline{\mathrm{CH}} 2011,2011)$. Figure 1 shows the assumed global greenhouse gas emissions pathways and the corresponding projected mean temperature changes for Switzerland (average of 2070-2099 relative to the average of 1980-2009) as presented in $\mathrm{CH} 2011$ (2011).
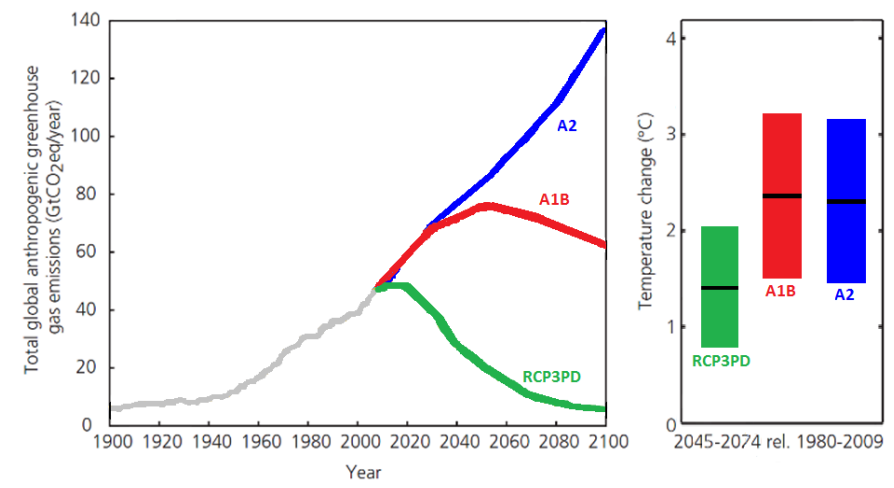

Figure 1: Pathways of past and future anthropogenic greenhouse gas emissions and projected annual mean warming for Switzerland for the 30-year average centered at 2060. Source:(CH2011. 2011)

A2 assumes high population growth and continued use of fossil fuels. In contrast, the A1B scenario assumes rapid economic growth and high technical 
progress. This reduces the dependence on fossil fuel and slows down population growth in the second half of the century. For 2060, the reference year of this analysis, temperature differences between A2 and A1B are very small. RCP3PD is an ambitious climate mitigation scenario, which has a $2 / 3$ likelihood of limiting global warming to $2^{\circ} \mathrm{C}$ above the preindustrial level.

For each of the three scenarios, we simulate impacts from the medium projected climate as well as from the upper and lower ends of a range corresponding formally to the $95 \%$ confidence interval generated by the climate model simulations. In fact, according to CH2014-Impacts (2014), "the expected chance that actual observed values will fall between the upper and the lower values is two in three for temperatures, and one in two for precipitation". Adding socioeconomic uncertainties to the picture further reduces the probability that the actual values will fall within the depicted ranges. This means that "upper" and "lower" should not be interpreted as confidence intervals. Rather, they represent possible ranges, which are consistent with the available data.

\subsection{Socio-economic assumptions}

To simulate the evolution of the economy until 2060, GEMINI-E3 uses projections of population growth, gross domestic product (GDP) and energy prices. We use the evolution of the Swiss population as defined by the scenario from the Federal Statistical Office. In 2060, 10.6 million inhabitants are projected to live in Switzerland. For the rest of the world, assumptions on population are based on the latest forecast by the United Nations. We use the "median-fertility variant". In 2060, the world population reaches 10.2 billion inhabitants.

For Switzerland, GDP growth is forecasted by the State Secretariat for Economic Affairs by multiplying the labor force (coming from the demographic scenario) with a labor productivity increase of $0.9 \%$ per year. For the rest of the world, we apply a similar methodology that is calibrated from the World Energy Outlook (WEO) (International Energy Agency, 2015).

Finally, assumptions concerning energy prices are also drawn from the WEO. The scenarios presented in this report assume, for the sake of simplification, that no stringent climate policy is implemented. Therefore, we retain the WEO scenario called "Current Policies Scenario". The predictions of the WEO stop in 2040. After that, we assume that energy prices will continue to grow at the rate of the previous decade. The oil price and the price of imported gas in Europe are assumed to reach 198 US\$ per barrel and 16.7 US\$ per Mbtu in 2060, respectively.

The basic assumptions about demographic and economic growth are not modified between scenarios. Sectoral impacts are taken into account in the general 
equilibrium analysis, but the fundamental drivers of growth can be considered robust to the CC impacts up to 2060. This avoids that differences in results arise mainly because of differences in socioeconomic assumptions rather than because of the CC hazards we are interested in.

\section{Climate-sensitive areas}

\subsection{Health}

A major part of $\mathrm{CC}$ impacts on health comes along with extreme weather events, such as heat waves, droughts and floods. According to the literature, heat waves constitute the highest CC hazard for human health in Switzerland (OcCC and ProClim, 2007; Ecoplan/Sigmaplan, 2007). Data availability and the challenge of monetization are the key issues when including health effects in a CGE analysis. Given the available data, we consider two health impacts in our model. Each of them can be attributed to very high temperatures during summer months:

- Excess mortality from cardiovascular and respiratory diseases due to heat stress;

- Loss of productivity of the workforce due to heat stress;

We also considered including increased health expenditures through hospitalizations due to heat stress. However, we abandoned the idea after our first calculations showed increases well below $0.01 \%$, at least in the absence of extreme heat events.

\subsubsection{Mortality}

We use the linear relationships between the number of days with daily maximum temperature above a certain threshold and an increase of mortality computed from Paci (2014). We compute the impacts by differentiating the population with respect to age and gender. Table 1 shows the impact of additional premature deaths that can be attributed to CC in 2060. For the A1B and A2 scenarios, about 650 premature deaths are estimated for the medium case, whereas the upper extremes with 928 (A1B) and 877 (A2) reach the level of excess mortality caused by the 2003 and 2015 heat waves. These figures show the number of premature deaths caused by cardiovascular and respiratory diseases on days with maximum temperature above certain thresholds. They do not cover heat wave effects that 
arise during a period of consecutive days with high temperatures..$^{4}$ In the high emissions scenarios, excess mortality reaches a level in 2060 which today is attained only by exceptional heat waves. Thus, we were not able to project damages and return periods for a heat event which would be more extreme than the 2060 average climate. However, as such events could come with a large death toll, it would be important to include them in the analysis.

The welfare cost associated to these premature death is calculated by multiplying the number of deaths by the standard value of a statistical life (VSL) in Switzerland. This VSL, used for the planning of natural hazard protection, is equal to 6.5 million $\mathrm{CHF}_{5}^{5}$ Taking into account income growth equal to our GDP projection, the VSL reaches 10 million CHF in 2060. Like in the PESETA project (Ciscar et al., 2012), this cost is not introduced in the GEMINI-E3 model, but simply added to the final welfare change computed by the model (see Section 5). Table 1 shows the CC impact on mortality in 2060.

Table 1: CC impacts on additional premature deaths due to cardiovascular and respiratory diseases in 2060

\begin{tabular}{lccc|ccc|ccc}
\hline & Lower & $\begin{array}{c}\text { RCP3PD } \\
\text { Medium }\end{array}$ & Upper & Lower & $\begin{array}{c}\text { A2 } \\
\text { Medium }\end{array}$ & Upper & Lower & $\begin{array}{c}\text { Medium } \\
\text { Upper }\end{array}$ \\
\hline Premature deaths & 213 & 380 & 532 & 402 & 662 & 928 & 337 & 641 & 877 \\
In million CHF 2016 & 2145 & 3820 & 5352 & 4045 & 6658 & 9331 & 3389 & 6449 & 8818 \\
in \% of HC & $0.33 \%$ & $0.59 \%$ & $0.82 \%$ & $0.62 \%$ & $1.02 \%$ & $1.43 \%$ & $0.52 \%$ & $0.99 \%$ & $1.35 \%$ \\
\hline
\end{tabular}

HC: Household consumption

\subsubsection{Productivity}

A causal link between temperature and labor productivity is documented in various studies based on biological evidence relating to human physiology e.g. Seppänen et al. (2006). Other research has investigated correlations of temperature with economic variables such as labor supply, wages, GDP, and highlights the need to integrate behavioral responses and cross sectoral effects (see the overview in Heal and Park, 2016). Exposure-response functions relating temperature to labor productivity allow for differentiating by work intensity and indoor vs. outdoor

\footnotetext{
${ }^{4}$ The magnitude of heat wave effects varies with duration and intensity of heat waves and geographical location. An analysis of 9 European cities by D'Ippoliti et al. (2010) showed an average increase in mortality among people over 65 years on heat wave days between $12.4 \%$ in the North Continental and $21.8 \%$ in the Mediterranean area.

${ }^{5}$ It is based on recent international transfer of values (Ecoplan, 2016) from a large willingnessto-pay meta-study (OECD, 2012)
} 
workplaces (Costa et al., 2016). Since the influence of humidity is essential for the reaction of the human body to temperature, these functions are based on Wet Bulb Globe Temperature (WBGT), which entails both temperature and humidity. Unfortunately, WBGT data are not available for Switzerland. ${ }^{6}$

We are thus confined to simplified approaches. Following the cantonal case studies, we set the productivity loss on a day with maximum temperature at $30^{\circ} \mathrm{C}$ or higher at $7 \%$. This does not take into account how long or how far above the threshold temperature rises, which may lead to an underestimation of the impact. Furthermore, we do not consider any depreciation in physical or mental capacity in the temperature range from $26^{\circ} \mathrm{C}$ and $30^{\circ} \mathrm{C}$. We assume that economic activity is distributed evenly over the 365 days of a year and that every member of the workforce is affected in the same manner independent of the location of the workplace (indoor/outdoor) or air-conditioning. The latter simplification is necessary, because there is no data available on the share of outdoor workers for Switzerland, neither for other countries. The impact of CC is calculated by deducting the number of hot days in the reference scenario from the respective numbers in the climate scenarios. Table 2 depicts the results of the CGE simulations with respect to productivity loss on hot days. It shows that high temperatures are going to have tangible effects on the economy in the course of CC. In the RCP3PD scenario, the decrease of household consumption due to productivity loss is still relatively small, ranging from $0.09 \%$ at the lower bound to $0.23 \%$ at the upper bound. However, at the upper ends of the A1B and A2 scenarios, it reaches more than $0.4 \%$ of household consumption.

Table 2: CC welfare impacts due to productivity loss - percentage change w.r.t reference case in 2060 (in \% of household consumption)

\begin{tabular}{lccc|ccc|ccc}
\hline & Lower & $\begin{array}{c}\text { RCP3PD } \\
\text { Medium }\end{array}$ & Upper & Lower & Medium & Upper & Lower & Medium & Upper \\
\hline Welfare change $^{a}$ & $-0.09 \%$ & $-0.17 \%$ & $-0.23 \%$ & $-0.17 \%$ & $-0.31 \%$ & $-0.41 \%$ & $-0.14 \%$ & $-0.31 \%$ & $-0.42 \%$ \\
\hline${ }^{a}$ in \% of households consumption.
\end{tabular}

\footnotetext{
${ }^{6}$ In an exploratory analysis we approximated WBGT with data of air temperature, wind speed, solar radiation and relative humidity from MeteoSwiss (hourly data for the worktime hours 8-12 and 13-17), following the algorithm of Liljegren et al. (2008). We confined the analysis to the year 2003, which had a particularly hot summer. In the end we have to accept that it is infeasible within our study to apply this approach to the climate scenarios in this paper.
} 


\subsection{Energy}

\subsubsection{Domestic impacts}

$\mathrm{CC}$ affects the energy sector on both the demand and the supply side.

On the supply side, the literature focuses on the effects of CC on hydropower production through a change in water flow regimes. Changes in runoff regimes are caused by changes in precipitation schemes as well as by temperature changes that affect melt water runoff from glaciers and snow cover. Hydropower is currently the most important source of electricity in Switzerland, accounting for approximately $60 \%$ of total electricity generation. While some seasonal shifts in runoff patterns may occur, the overall effect on hydropower production is expected to be small until 2060 (CH2014-Impacts, 2014). In a synthesis report on the impacts of climate change on hydropower, Weingartner et al. (2011) present temporally and spatially heterogeneous effects; while the Southern regions, especially Valais, can expect a slightly negative development of hydropower production volumes, the opposite is true for the alpine foothills. In the temporal dimension, increased meltwater flow from glaciers may continue pushing production volumes, but this effect may eventually revert, when many of those glaciers will have disappeared and cease producing meltwater altogether. The report concludes that near future changes in production volumes can be expected to be small, while producing country-wide results for the more distant future remains difficult. Economic valuations are presented by the cantonal case studies, which quantify the expected hydropower production change in 2060 with mixed results. The Aargau case study (Ernst Basler + Partner et al., 2013), for example, projects the expected economic impact on hydropower production due to a changed precipitation regime to be small in comparison to the impacts on the energy demand side. Hydropower production is projected to rise by $0.4 \%$ to $2.4 \%$. Fribourg on the other hand, expects precipitation and hydropower production to decrease by $2.5 \%$ to $4.9 \%$. Even stronger decreases are projected for the Canton Ticino, in the range of $4.2 \%$ to $6.8 \%$. As these regional results are ambiguous in a national setting and of rather small magnitude, we assume for the simulations that the Swiss electricity production sector would not be affected by $\mathrm{CC}$.

We thus concentrate on energy demand, where the literature focuses on the effects of CC for energy demand for heating and for cooling, due to the expected increase in average temperatures in winter and summer. Today, approximately a third of Switzerland's total final energy use is directed towards space heating, while around $2.5 \%$ is used for space cooling and ventilation (Kemmler et al. 2015). About three quarters of heating energy come from oil and natural gas. 
The change in heating and cooling energy demand is incorporated into GEMINIE3 using the methodology developed by Gonseth et al. (2017). The numbers of heating degree days (HDD) and cooling degree days (CDD) sum up differences between the outside temperature and a given interior target temperature to approximate energy demand for that particular year. For our target year 2060, HDDs are calculated as follows:

$$
H D D_{2060}\left(\theta^{*}, \theta_{t h}\right)=\sum_{k=1}^{365} m_{k}\left(\theta_{t h}\right) \cdot\left(\theta^{*}-\theta_{k}\right)
$$

with $m_{k}\left(\theta_{t h}\right)=1$ if $\theta_{k} \leq \theta_{t h}$ and $m_{k}\left(\theta_{t h}\right)=0$ otherwise.

In this equation $\theta^{*}$ is the target interior temperature, $\theta_{k}$ is the average daily temperature for day $k$ and $\theta_{t h}$ is the threshold outside temperature under which heating becomes necessary. The formula for HDD computes and sums daily differences between the target inside temperature and the outside temperature, but only when the daily mean temperature is lower than the threshold temperature in order to account for housing insulation. Values of the parameters of equation 1 that are commonly used for Switzerland are: $\theta^{*}=20^{\circ} \mathrm{C}$ and $\theta_{t h}=12^{\circ} \mathrm{C}$ (Christenson et al., 2006; Kirchner et al., 2010). Following Christenson et al. (2006), we assume that the energy demand for heating is proportional to the value of HDD.

The same method is applied for cooling energy demand and CDD. Cooling is only required when the outside temperature rises above the chosen threshold of $18.3^{\circ} \mathrm{C}$ (Christenson et al., 2006; Kirchner et al., 2010; Gonseth et al., 2017). With the help of a linear relation, the summed up CDD are then converted to specific electricity demand per surface, $D_{\text {spec }}$. More specifically, this relationship is quantified using the same approach as in the article by Gonseth et al. (2017), which in turn relies on a method presented by Aebischer et al. (2007):

$$
D_{2060}^{\text {spec }}=\frac{12.7+0.103 \times C D D_{2060}}{\left(1+\tau_{\text {cooling }}\right)^{2060-b}}
$$

Equation 2 presents the estimation of the annual specific electricity demand in KWh per $\mathrm{m}^{2}$ for cooled surfaces in $2060, D_{2060}^{\text {spec }}$. Ceteris paribus, an additional CDD thus increases electricity demand by $0.103 \mathrm{KWh}$ per cooled $\mathrm{m}^{2}$. $\tau_{\text {cooling }}$ represents technical progress, which is assumed to decrease specific energy requirement by $0.5 \%$ annually, starting from base year $b$ (2008). In addition to this demand change by surface area, future cooling energy demand depends on the development of the total commercial and residential area. A special challenge with cooling energy demand is that the currently low share of cooled surfaces is likely 
to increase with CC. To incorporate this effect, we use the estimation by Aebischer et al. (2007) for the future share of cooled area, which projects partially cooled surfaces to reach $40 \%$ and fully cooled surfaces $30 \%$ by 2060 (up from $20 \%$ and $19 \%$, respectively, in 2000). Putting the pieces together, total electricity demand from cooling in 2060, $E_{2060}$, is projected using the following equation:

$$
E_{2060}=D_{2060}^{\text {spec }} \times \text { Surface } \times\left(\alpha^{\text {full }}+\frac{\alpha^{\text {part }}}{4}\right)
$$

where $\alpha^{\text {full }}$ and $\alpha^{\text {part }}$ correspond to the share of fully and partly cooled surfaces respectively.

In Switzerland, global warming leads to a decrease in heating energy demand, which is partly countered by an increased energy demand for space cooling. The GEMINI-E3 simulation shows that the overall energy demand would decrease in 2060 under all three CC scenarios (see Table 3). The effect is more pronounced for the scenarios $\mathrm{A} 1 \mathrm{~B}$ and $\mathrm{A} 2$ (-1.74\% and $-1.70 \%$ energy energy consumption in the medium cases), which exhibit stronger warming than the RCP3PD scenario $(-1.02 \%)$. This implies not only that the decrease in energy demand for heating outweighs the increase in energy demand for cooling, but also that this gap widens as temperature increases. The changing pattern of energy usage can also explain the shift in the energy mix. The decrease in petroleum products can be attributed to a lower demand in heating oil. The projection with the weakest $\mathrm{CC}$ effect, RCP3PD lower, shows a decrease in petroleum product consumption of $1.13 \%$, while the projection for A1B upper, which contains the strongest CC signal, shows a decrease of $4.68 \%$. Electricity consumption, on the other hand, increases relatively strongly $(1.81-5.05 \%)$, which is due to the sharply increasing demand for cooling being predominantly powered by electricity. By 2060, a considerable part of this additional electricity is assumed to be generated from natural gas, counteracting some of the $\mathrm{CO}_{2}$ emission decreases caused by lower overall fossil fuel consumption. In total, the lower net energy consumption involves a welfare gain from $0.15 \%$ (RCP3PD medium) to $0.25 \%$ (A1B medium). Such positive welfare effects in the energy sector as we project for Switzerland can also be expected in other countries where the reduction in heating demand dominates. Nevertheless, these results should be regarded in the light of the underlying uncertainties. On the demand side, the future development of cooling is particulary hard to estimate, as current levels are very low. Hot summers, such as experienced recently in 2015 and 2018 could spur a quick increase in cooling in commercial and residential buildings. On the supply side, seasonal changes in run-off patterns 
may have a profound impact on hydropower production. However, such seasonal shifts are outside the scope of this study. Furthermore, these numbers reflect the climate change impact only, while the mitigation effort is kept constant between the climate scenarios.

Table 3: CC impact on heating and cooling demand in Switzerland, change to reference in 2060 in $\%$

\begin{tabular}{|c|c|c|c|c|c|c|c|c|c|}
\hline & Lower & $\begin{array}{l}\text { RCP3PD } \\
\text { Medium }\end{array}$ & Upper & Lower & $\begin{array}{c}\text { A1B } \\
\text { Medium }\end{array}$ & Upper & Lower & $\begin{array}{c}\text { A2 } \\
\text { Medium }\end{array}$ & Upper \\
\hline Energy consumption & $-0.40 \%$ & $-1.02 \%$ & $-1.62 \%$ & $-0.97 \%$ & $-1.74 \%$ & $-2.42 \%$ & $-0.93 \%$ & $-1.70 \%$ & $-2.38 \%$ \\
\hline Petroleum products & $-1.13 \%$ & $-2.11 \%$ & $-3.11 \%$ & $-2.12 \%$ & $-3.42 \%$ & $-4.68 \%$ & $-2.05 \%$ & $-3.36 \%$ & $-4.61 \%$ \\
\hline Natural gas & $-0.90 \%$ & $-2.06 \%$ & $-3.19 \%$ & $-1.99 \%$ & $-3.45 \%$ & $-4.77 \%$ & $-1.92 \%$ & $-3.39 \%$ & $-4.70 \%$ \\
\hline Electricity & $1.81 \%$ & $2.51 \%$ & $3.30 \%$ & $2.68 \%$ & $3.78 \%$ & $5.05 \%$ & $2.63 \%$ & $3.71 \%$ & $4.95 \%$ \\
\hline District heating & $-2.37 \%$ & $-4.39 \%$ & $-6.44 \%$ & $-4.41 \%$ & $-7.10 \%$ & $-9.71 \%$ & $-4.27 \%$ & $-6.97 \%$ & $-9.55 \%$ \\
\hline Welfare change $^{a}$ & $0.07 \%$ & $0.15 \%$ & $0.22 \%$ & $0.15 \%$ & $0.25 \%$ & $0.34 \%$ & $0.14 \%$ & $0.24 \%$ & $0.33 \%$ \\
\hline
\end{tabular}

\subsubsection{International price effects}

As Switzerland is a landlocked country and possesses large capacity for international power exchange ${ }^{7}$, development of electricity prices in the neighboring countries also affect Swiss prices and ultimately demand. For this reason, we incorporate the development of the electricity prices of Switzerland's European neighbors into GEMINI-E3, as predicted with the POLES model (Dowling, 2013). This study states relative CC cost impacts for individual European countries. Furthermore, the model is run under two climate scenarios and with four different climate models. Incorporated into the POLES model are both supply and demand side climate effects. On the supply side, the following $\mathrm{CC}$ effects are modelled:

- Efficiency decrease of thermal power plants due to a lack of cooling water;

- Change in productivity of renewable generation systems (hydro, wind and photovoltaic) due to an altered climate regime.

On the demand side, the effects of the changing temperature regime on both heating and cooling energy demand are modeled. The relative change resulting

\footnotetext{
${ }^{7}$ In 2015, Switzerland imported 42.3 TWh (73\% of end use) and exported 43.3 TWh (74\% of end use), with the largest part of imports coming from France and the largest outward flows directed to Italy.
} 
in the electricity production cost from all these effects in each country is then incorporated into GEMINI-E3's price signal for the electricity traded with other countries.

Dowling (2013) reports values for both 2030 and 2050 for the A1B and the E1 CC scenario. The E1 climate scenario was created by the European ENSEMBLES ${ }^{8}$ project and is similar to RCP3PD. We use the 2050 values presented in the work by Dowling (2013) as a basis to estimate the values for 2060 for the three scenarios simulated in this study (A1B, A2 and RCP3PD). We made adjustments along two dimensions to obtain the data for our purposes: the climate scenario and the temporal dimensions. For both dimensions, we assumed linear relationships between the change in the electricity price and the radiative forcing and inflated or deflated the results obtained by Dowling (2013) along radiative forcing. Table 4 presents the results of this calculation, that is the changes that are applied to European electricity prices in the GEMINI-E3 model runs.

Table 4: Climate change impact on European electricity prices, change to reference in 2060 in \%

\begin{tabular}{|c|c|c|c|c|c|c|c|c|c|}
\hline & Lower & $\begin{array}{l}\text { RCP3PD } \\
\text { Medium }\end{array}$ & Upper & Lower & $\begin{array}{c}\text { A1B } \\
\text { Medium }\end{array}$ & Upper & Lower & $\begin{array}{c}\text { A2 } \\
\text { Medium }\end{array}$ & Upper \\
\hline EU & $1.23 \%$ & $3.08 \%$ & $4.93 \%$ & $-0.49 \%$ & $-0.79 \%$ & $-1.22 \%$ & $-0.46 \%$ & $-0.78 \%$ & $-1.24 \%$ \\
\hline Germany & $1.65 \%$ & $4.11 \%$ & $6.58 \%$ & $-6.14 \%$ & $-9.83 \%$ & $-15.23 \%$ & $-5.72 \%$ & $-9.72 \%$ & $-15.44 \%$ \\
\hline France & $2.88 \%$ & $7.20 \%$ & $11.51 \%$ & $1.72 \%$ & $2.75 \%$ & $4.26 \%$ & $1.60 \%$ & $2.72 \%$ & $4.32 \%$ \\
\hline Italy & $0.41 \%$ & $1.03 \%$ & $1.64 \%$ & $0.74 \%$ & $1.18 \%$ & $1.83 \%$ & $0.69 \%$ & $1.17 \%$ & $1.85 \%$ \\
\hline Austria & $-0.41 \%$ & $-1.03 \%$ & $-1.64 \%$ & $0.49 \%$ & $0.79 \%$ & $1.22 \%$ & $0.46 \%$ & $0.78 \%$ & $1.24 \%$ \\
\hline
\end{tabular}

Although electricity prices change significantly in some countries, due in particular to mitigation costs for scenario RCP3PD, the impacts of these price changes for Switzerland are very small (see Table 5). The main reasons for this are the following:

- Import prices do not change much on average. Especially for A1B and A2, price increases in France are more than compensated by price decreases in Germany;

- The international exchange of electricity increased considerably in recent years. Swiss imports and exports each almost match domestic electricity generation. Yet, the net balance of trade in electricity is small. Depending on the future regulation of electricity markets, Swiss generation costs,

$\sqrt[8]{\text { http://ensembles-eu.metoffice.com/data.html }}$ 
which we assume to remain unaffected by $\mathrm{CC}$, will continue to influence end user prices to a considerable extent, especially for households. In scenario RCP3PD, Swiss generation even gains importance. It increases by about $0.3 \%$, because mitigation efforts abroad become a comparative disadvantage for foreign producers;

- While wholesale electricity prices are rather closely linked to generation costs, this is less true for end user prices, especially for households;

- Electricity consumption represents a small and shrinking share of household budgets, about half a percent in 2060 .

While the changes in French and German electricity markets will be an issue for managers in the Swiss electricity sector, the effects on Swiss consumers are very small. Where they exist, they are mostly a consequence of foreign mitigation measures in the electricity sector (scenario RCP3PD), not of modified climatic conditions.

Table 5: Impacts of foreign electricity price changes on Switzerland, change to reference in 2060 in $\%$

\begin{tabular}{lrrr|rrr|rrr}
\hline & \multicolumn{3}{c|}{ RCP3PD } & \multicolumn{3}{c|}{ A1B } & \multicolumn{2}{c}{ A2 } \\
& Lower & Medium & Upper & Lower & Medium & Upper & Lower & Medium & Upper \\
\hline Electricity cons. price & $0.61 \%$ & $1.52 \%$ & $2.42 \%$ & $-0.09 \%$ & $-0.14 \%$ & $-0.22 \%$ & $-0.08 \%$ & $-0.14 \%$ & $-0.22 \%$ \\
Electricity generation & $0.13 \%$ & $0.32 \%$ & $0.51 \%$ & $-0.02 \%$ & $-0.03 \%$ & $-0.05 \%$ & $-0.02 \%$ & $-0.03 \%$ & $-0.05 \%$ \\
Welfare change $^{a}$ & $-0.01 \%$ & $-0.02 \%$ & $-0.03 \%$ & $0.00 \%$ & $0.00 \%$ & $0.00 \%$ & $0.00 \%$ & $0.00 \%$ & $0.00 \%$ \\
\hline
\end{tabular}

${ }^{a}$ in \% of households consumption.

\subsection{Agriculture}

Agricultural production is exposed to a variety of $\mathrm{CC}$ hazards. The Federal Council's adaptation strategy (Swiss Confederation, 2012) identifies six such hazards: site suitability, heavy rainfall, drought, heat stress, pests, and price volatility. Henne et al. (2018) provide a recent compilation of climate change impacts in Switzerland with a focus on agriculture. They state that due to the variety of factors that influence performance in agricultural production, such as breeding, management options etc., it is difficult to attribute impacts to climate change. Further, due to the complex topography of Switzerland and resulting local variations in weather outcomes, inference about potential impacts of climate change can only be drawn for sub-regions of Switzerland. Such an example is provided by Holzkämper et al. (2015), where impacts of a changing climate on potential 
grain maize yields for the temporal scope of 2036-2065 are projected for three climatic regions in Switzerland. Results indicate that there are large uncertainties both from climate model chains and impact model approaches. For the case of grain maize, yield increases are projected for two regions, and a decrease for one region. Overall, Swiss agriculture could benefit from improved site suitability resulting from rising temperatures in some regions, and be adversely affected by changes in precipitation patterns (Henne et al., 2018). However, since the empirical basis for an economic quantification of impacts is still scarce and does not allow for a level of aggregation that is necessary for CGE modelling, we concentrate on international price effects in the quantitative assessment.

Some world regions, e.g. South America and parts of Asia are highly exposed and vulnerable to negative impacts of CC (Rosenzweig et al., 2014). As one third of Switzerland's agricultural imports originate from these regions, the impacts could be significant for Switzerland, e.g. in the form of higher prices for agricultural imports (INFRAS et al., 2007) and thus shifts in agricultural terms of trade.

Several studies offer information about $\mathrm{CC}$ induced price changes (Nelson et al., 2014; Rosenzweig et al., 2014). Wiebe et al. (2015) combine multiple climate and economic models to estimate the global and regional impacts of $\mathrm{CC}$ on agricultural yields and prices. To our knowledge, it is the only study that models different emission scenarios as well as price impacts for several crops. Thus, we use the price impacts derived in that study as data basis. Wiebe et al. (2015) make projections for four socioeconomic and climate scenarios: no CC, SSP1-RCP4.5, SSP2-RCP6.0, and SSP3-RCP8.5. Prices are reported for 2030 and 2050, and the percent deviations for the different emission scenarios are calculated relative to values without climate change.

To derive input data from Wiebe et al. (2015) for our emission scenarios and temporal scope, some data treatment is necessary. According to IPCC (2013), RCP4.5 results in approximately the same temperature change in 2040 as RCP3PD in 2060. In the absence of better information, we simply assume that the impacts on prices in the agricultural sector are linearly correlated with temperature increases. We thus project prices for RCP3PD in 2060 based on prices for RCP4.5 in 2040:

$\triangle P_{2060}(R C P 3 P D)=\triangle P_{2030}(R C P 4.5)+\frac{\triangle P_{2050}(R C P 4.5)-\triangle P_{2030}(R C P 4.5)}{2}$

Further, as an estimation for price deviations in scenarios A1B and A2 in 
2060, a linear function is derived from temperature change and price deviations of RCP6.0 in 2050 and applied to temperature change in A1B and A2.

Wiebe et al. (2015) model impacts on the crops coarse grains, rice, wheat, oilseeds, and sugar, with the first four being aggregated to the group 'grains and oil seeds'. They simulate 15 model runs ( 3 climate models combined with 5 economic models); we take the lowest / highest value for lower / upper and the mean of the 15 model runs. The projections for 2060, which are used as inputs to GEMINI-E3, are displayed in Table 6.

Table 6: Price deviations for grains and oil seeds (\% deviation from reference scenario in 2060)

\begin{tabular}{|c|c|c|c|c|c|c|c|c|c|}
\hline & \multicolumn{3}{|c|}{ RCP3PD } & \multicolumn{3}{|c|}{ A1B } & \multicolumn{3}{|c|}{ A2 } \\
\hline & Lower & Medium & Upper & Lower & Medium & Upper & Lower & Medium & Upper \\
\hline $\mathrm{CH}$ & - & - & - & - & - & - & - & - & - \\
\hline EU & 1.3 & 7.1 & 16.1 & 2.7 & 13.4 & 31.6 & 2.5 & 13.3 & 32.0 \\
\hline OECD & -1.0 & 7.8 & 29.6 & 0.6 & 11.2 & 36.3 & 0.6 & 11.1 & 36.8 \\
\hline USA & 0.9 & 6.0 & 13.9 & 0.8 & 7.2 & 23.7 & 0.8 & 7.2 & 24.0 \\
\hline BRIC & -3.6 & 5.8 & 14.8 & 4.8 & 15.8 & 30.8 & 4.5 & 15.6 & 30.8 \\
\hline ROW & 0.3 & 6.9 & 15.8 & 4.3 & 13.4 & 30.6 & 4.0 & 13.2 & 31.0 \\
\hline
\end{tabular}

The price changes presented above originate from costs and production changes for grains and oilseeds in the different world regions. They are replicated endogenously in GEMINI-E3 through changes in the productivity of inputs used in agriculture. The nested CES structure that is used to represent agricultural production is shown in Appendix B. These productivity changes lead to higher production costs and production declines in most regions (see Figure 2), such that market prices change as defined in Table 6. On a global average, the production of grains and oilseeds declines by $3.4 \%$ in the A1B scenario. For Switzerland, we assume no direct $\mathrm{CC}$ impacts on production, nevertheless, it increases by about $4 \%$ for $\mathrm{A} 1 \mathrm{~B}$ and $\mathrm{A} 2$ due to the comparative productivity improvement implied by productivity reductions abroad.

The changes in prices and quantities translate into considerable welfare changes at least for some parts of the world (see Figure 3). For example, the welfare reductions for BRIC and ROW countries are about $0.4 \%$ and $0.5 \%$ respectively in the $\mathrm{A} 1 \mathrm{~B}$ and $\mathrm{A} 2$ scenarios. The impacts are more severe in developing and emerging countries since their economies rely heavily on agriculture, especially grains and oilseeds productions. The projected welfare losses for Switzerland are $0.02 \%$ for $\mathrm{A} 1 \mathrm{~B}$ and $\mathrm{A} 2$ (up to $0.05 \%$ in the upper range, $0.03 \%$ for RCP3PD medium). This reflects the low dependency of the Swiss economy on agriculture. 


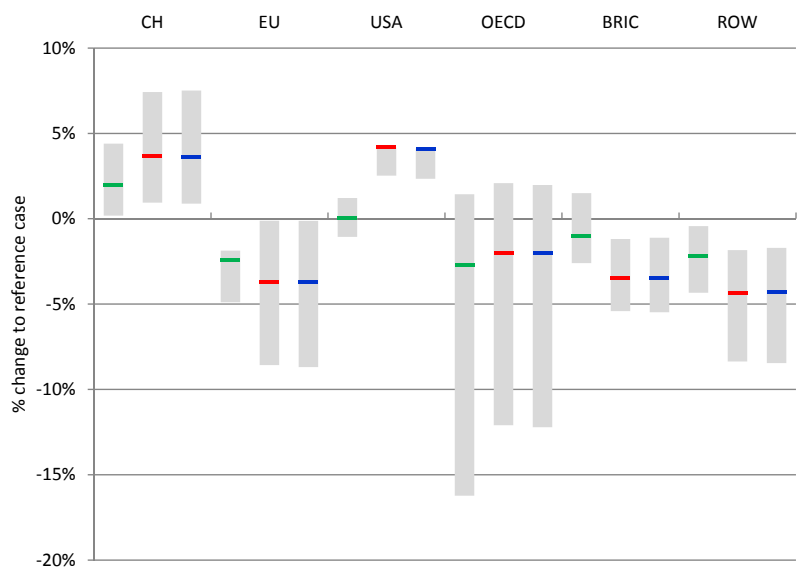

Figure 2: Production of grains and oilseeds under the three scenarios in 2060 (\% deviation from reference scenario)

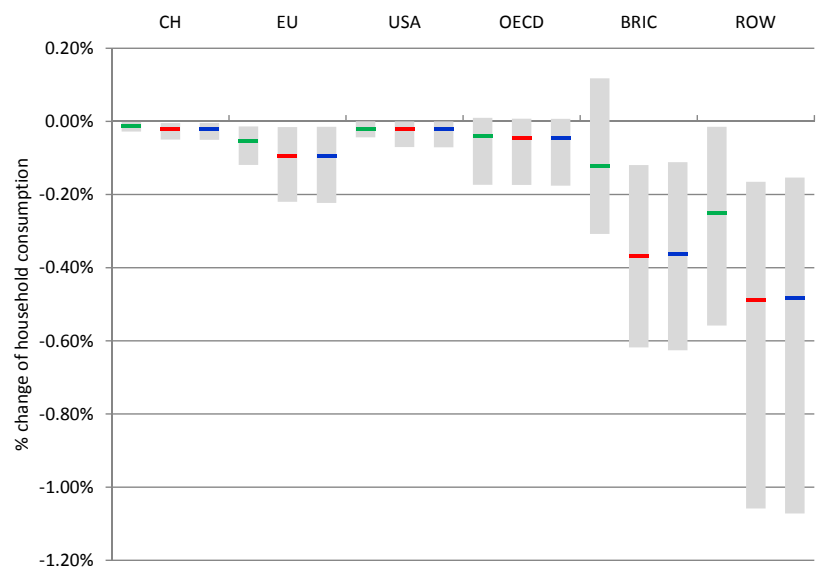

Figure 3: Regional welfare changes due to impacts on agriculture under the three scenarios

\subsection{Water management}

We include in water management the preparation and distribution of drinking water and industrial water (used in irrigation, production and cooling), as well as the collection, treatment and disposal of waste water. According to the $\mathrm{CH} 2014-$ Impacts (2014) report, Swiss total annual river runoff will remain approximately constant in 2060. However, seasonal patterns of water resources will shift, de- 
creasing in summer and increasing in winter. This will mainly affect the irrigation of crop farming and horticulture (i.e. plant production). We thus concentrate on climate-induced changes in summer river runoff used for plant production in Switzerland.

Raw water resources are introduced as a production factor into the model and a drinking water distribution sector is specified for Switzerland to allow for a precise analysis of the economic consequences of restricted water supply (see for more details, Appendix B and Faust et al., 2015).

In the absence of extreme droughts, water scarcity is an issue in only few agricultural areas of Switzerland. Regions where demand potentially reaches a critical share of river runoff supply are identified by Fuhrer and Calanca (2014). For eight critical regions and based on cantonal data, we estimate vulnerable plant production as a share of total plant production in Switzerland in 2015. Summer runoff changes are only applied to the affected shares of Swiss plant production. The weighted changes in the critical regions are aggregated to attain numbers for Switzerland as a whole. Given that the critical regions contribute only $21 \%$ of total plant production, the change in critical summer runoff is small relative to total summer runoff in Switzerland. In addition, we consider that summer runoff accounts for $60 \%$ of the total irrigation water resource, the remainder being groundwater. As a result, critical changes of the irrigation water resource represent only a small fraction of the total irrigation water resource for Switzerland (see Table 7).

Table 7: Critical changes of the irrigation water resource (\% deviation from total irrigation water resource in the reference scenario in 2060)

\begin{tabular}{|c|c|c|c|c|c|c|c|c|}
\hline Lower & $\begin{array}{l}\text { RCP3PD } \\
\text { Medium }\end{array}$ & Upper & Lower & $\begin{array}{c}\text { A1B } \\
\text { Medium }\end{array}$ & Upper & Lower & $\begin{array}{c}\text { A2 } \\
\text { Medium }\end{array}$ & Upper \\
\hline$-0.50 \%$ & $-4.73 \%$ & $-8.04 \%$ & $-2.62 \%$ & $-6.49 \%$ & $-10.89 \%$ & $-2.19 \%$ & $-6.06 \%$ & $-10.46 \%$ \\
\hline
\end{tabular}

With the input data presented above, it comes as no surprise that the macroeconomic impacts are extremely small. Welfare changes in terms of total consumption do not exceed 5.4 million CHF of 2016 (Table 8). Even if price changes for raw irrigation water are large, impacts are modest, because price levels for raw water and the cost share in agricultural production are extremely low. Hence, the low welfare effect and the high price changes for raw water can both be explained, because there is no need for agricultural producers to change their decisions, even 
if prices change. Moreover, the small macro-economic importance of plant production further limits the significance of the impacts.

Table 8: Impacts of changes in the irrigation water resource (\% deviation from reference scenario in 2060)

\begin{tabular}{|c|c|c|c|c|c|c|c|c|c|}
\hline & \multicolumn{3}{|c|}{ RCP3PD } & \multicolumn{3}{|c|}{ A1B } & \multicolumn{3}{|c|}{ A2 } \\
\hline & Lower & Medium & Upper & Lower & Medium & Upper & Lower & Medium & Upper \\
\hline Raw water prices & $6.7 \%$ & $73.7 \%$ & $139.3 \%$ & $37.9 \%$ & $107.0 \%$ & $206.2 \%$ & $31.2 \%$ & $98.5 \%$ & $195.4 \%$ \\
\hline Raw water consumption & & & & & & & & & \\
\hline Grains and oil seeds & $-0.5 \%$ & $-4.5 \%$ & $-7.7 \%$ & $-2.5 \%$ & $-6.2 \%$ & $-10.5 \%$ & $-2.1 \%$ & $-5.8 \%$ & $-10.1 \%$ \\
\hline Other crops & $-0.6 \%$ & $-5.1 \%$ & $-8.7 \%$ & $-2.8 \%$ & $-7.0 \%$ & $-11.7 \%$ & $-2.4 \%$ & $-6.5 \%$ & $-11.3 \%$ \\
\hline Production & & & & & & & & & \\
\hline Grains and oil seeds & $0.0 \%$ & $-0.2 \%$ & $-0.3 \%$ & $-0.1 \%$ & $-0.2 \%$ & $-0.4 \%$ & $-0.1 \%$ & $-0.2 \%$ & $-0.4 \%$ \\
\hline Other crops & $0.0 \%$ & $-0.1 \%$ & $-0.1 \%$ & $0.0 \%$ & $-0.1 \%$ & $-0.2 \%$ & $0.0 \%$ & $-0.1 \%$ & $-0.2 \%$ \\
\hline Welfare change $^{a}$ & $0.00 \%$ & $0.00 \%$ & $0.00 \%$ & $0.00 \%$ & $0.00 \%$ & $0.00 \%$ & $0.00 \%$ & $0.00 \%$ & $0.00 \%$ \\
\hline
\end{tabular}

${ }^{a}$ in $\%$ of households consumption.

\subsection{Tourism}

Being highly dependent on weather and climate, the tourism industry is particularly vulnerable to $\mathrm{CC}$ impacts. It represents a significant part of the Swiss economy, accounting for $2.6 \%$ of GDP and for $4.1 \%$ of total employment in 2015 $(\overline{F S O})$, with high regional disparity. Regarding $\mathrm{CC}$, winter tourism seems particularly affected. The increase in temperatures will decrease the annual mean snow depth by about $50 \%$ in 2060, and the number of snow-reliable ski areas could decrease by $29 \%$ in the A 2 scenario and without snowmaking (CH2014-Impacts, 2014). On the other hand, tourism in general could benefit from a longer summer season. The emergence of new lakes in the alpine regions, the development of new trails and climbing routes due to glacier retreat and an improvement of the thermal comfort could make Switzerland more attractive (Matasci, 2010).

Gonseth and Vielle (2017) performed a detailed study of the CC impacts on winter tourism using GEMINI-E3. They disaggregated total tourism into three sectors: "winter overnight tourism" (WOT), "one-day winter tourism" (ODT) and "other forms of tourism" (OFT). We build on their work, keeping the same representation, updating the analysis for winter tourism and extending it for summer tourism.

\subsection{Winter tourism}

The WOT sector represents skiers spending one or several nights in a ski resort. A consumer can take a ski trip in any of the regions included in GEMINI-E3. The ODT sector represents skiers spending only one day in a ski resort. In the 
model, only Swiss agents consume this good, because the respective consumption of foreign residents is almost negligible. The production function of the winter tourism sectors includes as a production factor natural snow that can be substituted with artificial one (i.e. snowmaking facilities, see Appendix C). The ODT sector is more vulnerable to a snow decrease than the WOT sector. Indeed, oneday skiers mainly go to close to home ski resorts, which are located at lower altitudes. Since it is more difficult to produce artificial snow at lower altitudes due to shorter and less frequent periods of cold weather, the ODT sector has a limited adaptation capacity (Gonseth and Vielle, 2017). This greater vulnerability is represented in GEMINI-E3 through a lower elasticity of substitution between natural and artificial snow for the ODT sector.

We calculate the variation in snow endowment using the variable "Fractional Snow Cover" from ENSEMBLES and CORDEX projects? We extract data for Switzerland, Germany, Austria, France and Italy and aggregate them to GEMINIE3 regions (Switzerland and Europe). Only two climate scenarios, RCP3PD and A1B are represented in these databases. Outside Europe, without additional information, we assume as Gonseth and Vielle (2017) that the reductions in snow resources are approximatively similar to the ones computed for the EU (respectively $-4 \%$ in the RCP3PD scenario and $-20 \%$ in the A1B scenario).

In scenario A1B (see Table 9), the producer price increases by $5.1 \%$ for ODT and by $1.6 \%$ for WOT. The two price increases are not similar since the CC impacts on the snow resource vary across segments $(-21.8 \%$ for ODT and $-12.5 \%$ for WOT). The difference also arises, because adaptation capacities on the supply and demand sides are different in the two segments. Due to these price variations, production decreases by $2.8 \%$ in ODT, but increases by $0.6 \%$ in WOT. Indeed, Swiss WOT benefits from relative competitiveness improvements, as the impacts of CC on winter tourism are more significant outside Switzerland. Therefore, Swiss exports (foreign tourists visiting Switzerland) increase and Swiss imports (Swiss tourists abroad) decrease. This induces some welfare improvement, which is however limited $(<0.01 \%)$.

In the RCP3PD scenario, the decrease in snow endowment is very small, as are the economic impacts on Swiss winter tourism. WOT production change ranges between $-0.1 \%$ to $0.0 \%$ and ODT production decreases by $0.4 \%$. Welfare remains essentially unchanged with respect to the baseline scenario.

In short, even if welfare impacts are slightly positive, the situation is mixed

\footnotetext{
ghttp://www.cordex.org/
} 
Table 9: Impacts of climate CC for the Swiss winter tourism sector and welfare (\% deviation from reference scenario in 2060)

\begin{tabular}{|c|c|c|}
\hline & RCP3PD & A1B \\
\hline \multicolumn{3}{|c|}{ Variations in snow endowment for WOT } \\
\hline $\mathrm{CH}$ & $-2.0 \%$ & $-12.5 \%$ \\
\hline EU & $-3.4 \%$ & $-23.4 \%$ \\
\hline OECD & $-4.0 \%$ & $-20.0 \%$ \\
\hline USA & $-4.0 \%$ & $-20.0 \%$ \\
\hline BRIC & $-4.0 \%$ & $-20.0 \%$ \\
\hline ROW & $-4.0 \%$ & $-20.0 \%$ \\
\hline \multicolumn{3}{|c|}{ Variations in snow endowment for $O D T$} \\
\hline $\mathrm{CH}$ & $-4.0 \%$ & $-21.8 \%$ \\
\hline \multicolumn{3}{|l|}{ Swiss WOT } \\
\hline Production & $0.0 \%$ & $0.0 \%$ \\
\hline Consumption & $-0.2 \%$ & $-1.2 \%$ \\
\hline Exports & $0.2 \%$ & $2.3 \%$ \\
\hline Imports & $-0.4 \%$ & $-3.7 \%$ \\
\hline Artificial snow & $1.4 \%$ & $10.5 \%$ \\
\hline Producer price & $0.2 \%$ & $1.6 \%$ \\
\hline \multicolumn{3}{|l|}{ Swiss ODT } \\
\hline Production & $-0.4 \%$ & $-2.8 \%$ \\
\hline Consumption & $-0.4 \%$ & $-2.8 \%$ \\
\hline Artificial snow & $1.0 \%$ & $7.2 \%$ \\
\hline Producer price & $0.7 \%$ & $5.1 \%$ \\
\hline Welfare change ${ }^{a}$ & $0.0005 \%$ & $0.0281 \%$ \\
\hline
\end{tabular}

${ }^{a}$ in $\%$ of households consumption. 
among segments. Production of the one-day winter tourism sector decreases in all scenarios, highlighting the greater vulnerability of ski resorts located at low altitudes, since they suffer from a greater natural snow loss. Higher ski resorts benefit from their comparative advantage with respect to lower altitude resorts in Switzerland and in the EU. However, their vulnerability also increases, because the decrease in natural snow raises their production costs.

\subsection{Summer tourism}

In order to model the variations in tourism flows, we use the Hamburg Tourism Model (HTM) developed by Hamilton et al. (2005). The purpose of the model is to understand how the current pattern of tourism flows may change under scenarios of future population growth, economic growth and CC. Results from the model have already been implemented successfully in CGE models to analyze scenarios of CC and climate policies (Berrittella et al., 2006; Bosello et al., 2012).

Since we focus on CC effects, we remove the socioeconomic scenario effects (increase of population and GDP) to allow for meaningful comparisons between CC scenarios A1B, A2 and RCP3PD. To do this, we calculate the variations of tourists with respect to the same scenario without $\mathrm{CC}$. The results of the simulations with the HTM are then used as input data for GEMINI-E3. The destination flows computed from CES functions in GEMINI-E3 are modified according to the variations calculated with the HTM. We assume that the results of the HTM simulations correspond to the OFT (other forms of tourism) sector, because the HTM is calibrated on summer tourism.

International tourism flows change according to the new temperature pattern. Cooler countries like Canada, Norway or Russia become more attractive. Thus, regions OECD and BRIC get more arrivals. On the other hand, temperature increase reduces international tourism flows, i.e. total international departures and arrivals decrease while domestic tourism increases. On aggregate, the Swiss tourism sector benefits from this effect. Indeed, even if international tourists spend less in Switzerland, Swiss tourists also spend less outside Switzerland and more at home. For example in 2060 in scenario A2, arrivals decrease by $1.9 \%$ to $5.2 \%$ while departures decrease by $9.6 \%$ to $18.9 \%$ (Figure 4 ).

The reallocation of tourism flows translates into welfare changes. In 2060, Switzerland is better off in all scenarios except RCP3D Lower. Switzerland benefits from larger increases in temperature, although to a lesser extent than GEMINIE3's OECD region, which is the main winner. One explanation for the benefits to Switzerland is that more tourists will enjoy cooler mountain areas at the expense of hot city or seaside destinations. Moreover, the summer tourism season in alpine 

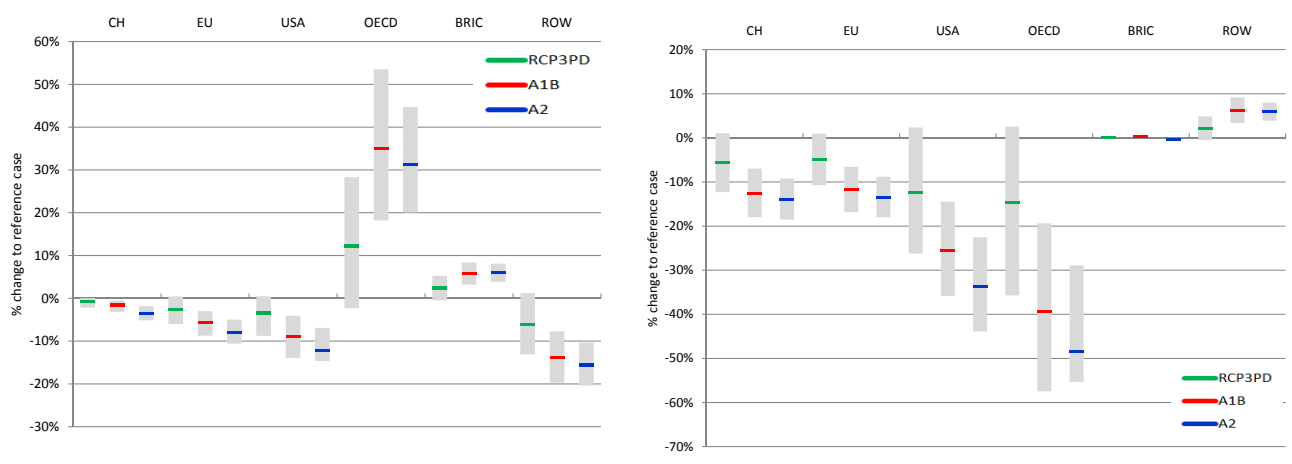

Figure 4: International touristic arrivals (left) and departures (right) (\% deviation from reference scenario in 2060)

areas could expand to spring and autumn. Thus, the decrease in arrivals is more than compensated for by the decrease in departures and the increase in domestic tourism. The projected welfare gain is moderate, with a maximum of $0.21 \%$ in scenario A1B upper.

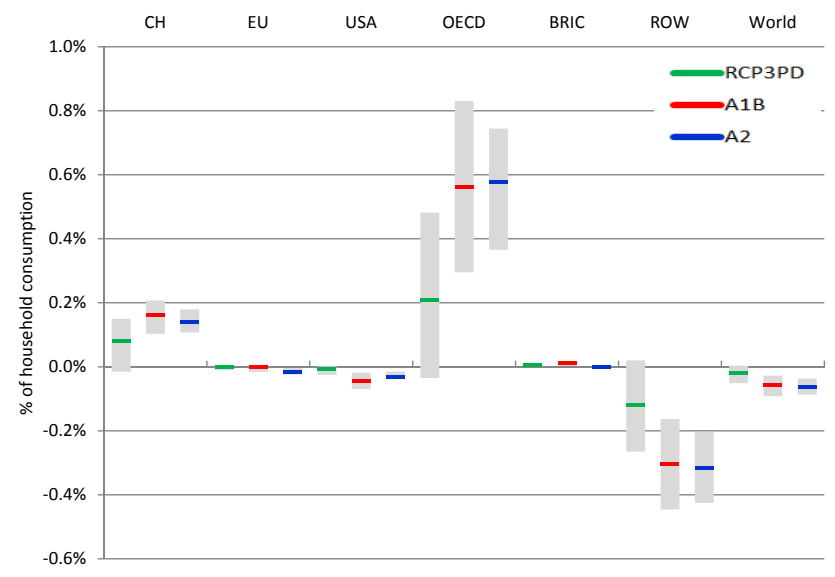

Figure 5: Regional welfare changes due to impacts on summer tourism under the three scenarios in 2060 


\section{Aggregated impacts}

To include interaction effects between the considered impacts and arrive at a rough and still incomplete estimate of total impacts, we simulate the different selected CC hazards together.

For winter tourism, only medium scenarios RCP3PD and A1B are simulated due to the lack of data on snow projections. Without additional information we assume that the impacts are the same for lower, medium and upper cases. Finally, the monetary costs of premature deaths are directly added to the welfare changes computed by the model.

Table 10 depicts the aggregated impacts of CC in Switzerland in 2060. Considering the omission of important impacts (especially weather events more extreme than the 2060 average), the numbers must be interpreted with caution. For scenarios A1B and A2, the GDP loss caused by the selected impacts is significant, between $0.15 \%$ and $0.41 \%$. Even in the ambitious climate stabilization scenario RCP3PD, Switzerland will suffer from CC impacts, but the cost is only between $0.08 \%$ and $0.25 \%$ of GDP. The welfare loss is more important, reaching between 2 to 9 billion $\mathrm{CHF}$ in the $\mathrm{A} 1 \mathrm{~B}$ and $\mathrm{A} 2$ scenarios. In the most pessimistic warming scenario, it represents around $1.4 \%$ of household consumption in 2060 . International trade effects (i.e. changes in Swiss imports and exports) are mainly driven by the impacts of $\mathrm{CC}$ on agriculture (mainly on imports) and summer tourism (both on exports and imports).

At the sectoral level, sectors related to energy consumption for heating (district heating, natural gas and refined petroleum products) are affected most. They are followed by one-day winter tourism. Then come the 'other' agricultural sectors, industry, insurance and land transport. Production increases in few sectors. That is the case for summer tourism, electricity and for the grains and oil seeds sector, which benefits from comparative productivity improvements with respect to other world regions.

It is interesting to decompose the welfare impact by areas. This is done in Table 11, where the welfare changes computed for each impact represented in this paper are detailed. They are computed from the simulations results realized in the previous sections. Health impacts (i.e. mortality and productivity loss) are the most serious $\mathrm{CC}$ impacts, with a cost ranging from 5 to 12 billion of $\mathrm{CHF}$ in scenarios $\mathrm{A} 1 \mathrm{~B}$ and $\mathrm{A} 2$. Losses in agriculture are also significant and reach 0.3 billion of $\mathrm{CHF}$ in the worst case (A2 upper). The simulations also show some positive impacts. With a warmer climate, less energy will be needed to heat buildings, the estimated gain ranges from 0.9 to 2.2 billion $\mathrm{CHF}$ in scenarios 
A1B and A2. Tourism will also benefit from better climate conditions compared to other regions, the gain ranging from 0.7 to 1.3 billions $\mathrm{CHF}$ in the same scenarios.

The other impacts studied in this paper are of lesser importance.

Table 10: Aggregated impacts of CC (\% deviation from reference scenario in 2060)

\begin{tabular}{|c|c|c|c|c|c|c|c|c|c|}
\hline & \multicolumn{3}{|c|}{ RCP3PD } & \multicolumn{3}{|c|}{ A1B } & \multicolumn{3}{|c|}{ A2 } \\
\hline & Lower & Medium & Upper & Lower & Medium & Upper & Lower & Medium & Upper \\
\hline GDP & $-0.08 \%$ & $-0.17 \%$ & $-0.25 \%$ & $-0.18 \%$ & $-0.30 \%$ & $-0.41 \%$ & $-0.15 \%$ & $-0.29 \%$ & $-0.40 \%$ \\
\hline Imports & $-0.01 \%$ & $-0.22 \%$ & $-0.49 \%$ & $-0.13 \%$ & $-0.37 \%$ & $-0.69 \%$ & $-0.19 \%$ & $-0.44 \%$ & $-0.75 \%$ \\
\hline Households cons. & $-0.06 \%$ & $-0.06 \%$ & $-0.07 \%$ & $0.00 \%$ & $-0.06 \%$ & $-0.12 \%$ & $0.03 \%$ & $-0.07 \%$ & $-0.16 \%$ \\
\hline Government cons. & $0.00 \%$ & $0.00 \%$ & $0.00 \%$ & $0.00 \%$ & $0.00 \%$ & $0.00 \%$ & $0.00 \%$ & $0.00 \%$ & $0.00 \%$ \\
\hline Investment & $-0.09 \%$ & $-0.13 \%$ & $-0.21 \%$ & $-0.05 \%$ & $-0.16 \%$ & $-0.31 \%$ & $-0.03 \%$ & $-0.19 \%$ & $-0.35 \%$ \\
\hline Exports & $-0.04 \%$ & $-0.36 \%$ & $-0.69 \%$ & $-0.35 \%$ & $-0.67 \%$ & $-1.03 \%$ & $-0.41 \%$ & $-0.71 \%$ & $-1.04 \%$ \\
\hline \multicolumn{10}{|l|}{ Change in $\%$ of production } \\
\hline Natural gas & $-1.33 \%$ & $-2.76 \%$ & $-4.17 \%$ & $-2.97 \%$ & $-5.03 \%$ & $-6.97 \%$ & $-2.85 \%$ & $-4.93 \%$ & $-6.86 \%$ \\
\hline Petroleum products & $-0.84 \%$ & $-1.37 \%$ & $-1.91 \%$ & $-1.43 \%$ & $-2.30 \%$ & $-3.10 \%$ & $-1.36 \%$ & $-2.27 \%$ & $-3.09 \%$ \\
\hline Electricity & $1.13 \%$ & $1.65 \%$ & $2.22 \%$ & $1.47 \%$ & $1.99 \%$ & $2.63 \%$ & $1.45 \%$ & $1.97 \%$ & $2.59 \%$ \\
\hline District heating & $-2.36 \%$ & $-4.56 \%$ & $-6.75 \%$ & $-4.63 \%$ & $-7.48 \%$ & $-10.24 \%$ & $-4.49 \%$ & $-7.31 \%$ & $-10.04 \%$ \\
\hline Grains and oil seeds & $0.14 \%$ & $1.65 \%$ & $3.80 \%$ & $0.63 \%$ & $3.07 \%$ & $6.55 \%$ & $0.59 \%$ & $3.09 \%$ & $6.69 \%$ \\
\hline Other crops & $-0.01 \%$ & $-0.39 \%$ & $-0.75 \%$ & $-0.41 \%$ & $-0.78 \%$ & $-1.22 \%$ & $-0.43 \%$ & $-0.73 \%$ & $-1.15 \%$ \\
\hline Animals & $-0.04 \%$ & $-0.21 \%$ & $-0.32 \%$ & $-0.31 \%$ & $-0.44 \%$ & $-0.48 \%$ & $-0.29 \%$ & $-0.39 \%$ & $-0.42 \%$ \\
\hline Forestry & $-0.04 \%$ & $-0.24 \%$ & $-0.38 \%$ & $-0.31 \%$ & $-0.46 \%$ & $-0.55 \%$ & $-0.30 \%$ & $-0.41 \%$ & $-0.49 \%$ \\
\hline Industry & $-0.07 \%$ & $-0.42 \%$ & $-0.65 \%$ & $-0.64 \%$ & $-0.91 \%$ & $-1.03 \%$ & $-0.61 \%$ & $-0.80 \%$ & $-0.88 \%$ \\
\hline Land transport & $-0.07 \%$ & $-0.23 \%$ & $-0.35 \%$ & $-0.24 \%$ & $-0.42 \%$ & $-0.57 \%$ & $-0.21 \%$ & $-0.40 \%$ & $-0.56 \%$ \\
\hline Sea transport & $-0.07 \%$ & $-0.05 \%$ & $-0.02 \%$ & $0.01 \%$ & $0.00 \%$ & $-0.04 \%$ & $0.07 \%$ & $0.02 \%$ & $-0.05 \%$ \\
\hline Air transport & $-0.06 \%$ & $-0.19 \%$ & $-0.31 \%$ & $-0.17 \%$ & $-0.32 \%$ & $-0.49 \%$ & $-0.13 \%$ & $-0.29 \%$ & $-0.49 \%$ \\
\hline Insurance & $-0.05 \%$ & $-0.31 \%$ & $-0.58 \%$ & $-0.36 \%$ & $-0.64 \%$ & $-0.99 \%$ & $-0.29 \%$ & $-0.49 \%$ & $-0.72 \%$ \\
\hline Health & $-0.06 \%$ & $-0.05 \%$ & $-0.05 \%$ & $-0.01 \%$ & $-0.06 \%$ & $-0.10 \%$ & $0.01 \%$ & $-0.08 \%$ & $-0.14 \%$ \\
\hline Services & $-0.05 \%$ & $-0.13 \%$ & $-0.21 \%$ & $-0.13 \%$ & $-0.24 \%$ & $-0.34 \%$ & $-0.12 \%$ & $-0.24 \%$ & $-0.34 \%$ \\
\hline Winter overnight tourism & $0.02 \%$ & $-0.26 \%$ & $-0.49 \%$ & $0.33 \%$ & $0.11 \%$ & $-0.13 \%$ & $0.35 \%$ & $0.17 \%$ & $-0.07 \%$ \\
\hline One-day winter tourism & $-0.41 \%$ & $-0.46 \%$ & $-0.50 \%$ & $-2.84 \%$ & $-2.88 \%$ & $-2.92 \%$ & $-2.84 \%$ & $-2.91 \%$ & $-2.95 \%$ \\
\hline Other forms of tourism & $-0.38 \%$ & $0.97 \%$ & $1.94 \%$ & $1.54 \%$ & $2.28 \%$ & $2.73 \%$ & $1.64 \%$ & $1.79 \%$ & $1.91 \%$ \\
\hline Drinking water & $-0.03 \%$ & $-0.03 \%$ & $-0.03 \%$ & $-0.03 \%$ & $-0.06 \%$ & $-0.08 \%$ & $-0.02 \%$ & $-0.07 \%$ & $-0.10 \%$ \\
\hline \multicolumn{9}{|l|}{ Welfare change } & -8561 \\
\hline in $\%$ of $\mathrm{HC}$ & $-0.37 \%$ & $-0.57 \%$ & $-0.76 \%$ & $-0.55 \%$ & $-0.96 \%$ & $-1.37 \%$ & $-0.42 \%$ & $-0.95 \%$ & $-1.34 \%$ \\
\hline
\end{tabular}

HC: Household consumption.

We can compare the benefits of limiting global warming estimated in this paper with the costs associated to a deep decarbonization pathway for Switzerland. These mitigation costs have been estimated with GEMINI-E3 in scenarios that assume $76 \%$ abatement with respect to 1990 levels and are thus considered compatible with the $2^{\circ} \mathrm{C}$ long term target (Babonneau et al. 2018). The estimated mitigation costs lie thin the range of $1.45 \%$ to $1.93 \%$ of household consumption in 2050. This is of comparable magnitude to the costs of CC for Switzerland computed in this paper. However, this formal cost-benefit analysis does not integrate several aspects that would increase the benefits of limiting CC. They include the 
Table 11: Decomposition of welfare impacts of CC in million $\mathrm{CHF}_{2016}$ in 2060

\begin{tabular}{lrrr|rrr|rrr}
\hline & \multicolumn{3}{c}{ RCP3PD } & \multicolumn{3}{c}{ A1B } & \multicolumn{3}{c}{ A2 } \\
& Lower & Medium & Upper & Lower & Medium & Upper & Lower & Medium & Upper \\
\hline Mortality & -2145 & -3820 & -5352 & -4045 & -6658 & -9331 & -3389 & -6449 & -8818 \\
Productivity loss & -574 & -1086 & -1489 & -1107 & -1950 & -2607 & -919 & -1958 & -2713 \\
Heating-Cooling & 454 & 944 & 1432 & 930 & 1566 & 2161 & 898 & 1537 & 2127 \\
International energy prices & -55 & -133 & -211 & 8 & 12 & 19 & 7 & 11 & 19 \\
Agriculture & -9 & -80 & -179 & -30 & -138 & -318 & -28 & -137 & -322 \\
Water management & 0 & -3 & -4 & -1 & -4 & -5 & -1 & -3 & -5 \\
Winter tourism & 3 & 3 & 3 & 35 & 35 & 35 & 35 & 35 & 35 \\
Summer tourism & -64 & 520 & 953 & 667 & 1032 & 1314 & 691 & 900 & 1137 \\
\hline
\end{tabular}

precautionary principle, the impacts of extreme events, the loss of non-monetary assets (e.g. natural ecosystems) and the benefits of reducing CC abroad (e.g. in developing countries). Taking them into account would clearly tilt the balance in favor of deep decarbonization in Switzerland. Furthermore, one can argue that the more relevant cost-benefit analysis is at the global level, with individual countries' contributions to mitigation following the UNFCCC's principle of common, but differentiated responsibilities.

\section{Conclusion}

This paper presents a comprehensive overview of economic impacts of CC in Switzerland to be expected in 2060. Next to a thorough appraisal of the existing literature, we improved the monetary quantification of the impacts of CC on Switzerland in the context of general equilibrium analysis. In particular, we newly included the most important trade related cross-border impacts, notably in summer tourism, grain agriculture and electricity supply. Analyses for domestic impacts have been updated to reflect the latest literature and data.

We concentrated in the simulations on a selection of impacts that are important according to existing literature and for which adequate data are available. Some potentially significant impacts have not yet been quantified in a satisfactory way, e.g. impacts of disastrous extreme events such as heat waves and droughts which would be more extreme than the 2060 average climate. Thus, simulations of aggregate impacts do not serve the purpose to generate meaningful numbers for total climate change impacts in Switzerland, but to include interaction effects between different sectoral impacts. Admittedly, such interaction effects result to be very small for the impacts considered.

For the individual impacts, numbers are somewhat more reliable than at the aggregate level. We provide ranges of results, covering different climate scenarios 
and ranges of results from bottom-up simulations and studies, which we used to derive input data for our applied general equilibrium analysis. Formally departing from $95 \%$ confidence intervals for temperature and precipitation changes, combined multi-level uncertainties imply that the ranges of results are merely rough indications. For some sectors, we can at least be highly confident in the overall direction of the welfare change: health (-), agricultural imports (-), tourism (+), energy demand $(+)$.

Impacts on human health are among the most serious of CC impacts in Switzerland, with summer heat waves being the main cause. Agriculture and forestry are particularly sensitive to climate and weather conditions. Despite these risks, the overall vulnerability of Swiss agriculture seems to be rather small. Tourism is another sector where international aspects are particularly important, given that more than 9 million foreign tourists visit Switzerland per year, more than its entire population. The main concern for tourism with respect to $\mathrm{CC}$ is the retreating snow cover, which constitutes a serious challenge to ski resorts, especially below an altitude of about $1800 \mathrm{~m}$. At the same time, Swiss summer tourism benefits from new climatic conditions, and its activity is likely to increase in the future decades, thus overcompensating losses that will occur in some segments of winter tourism. Concerning energy demand, we found significant welfare gains, mainly from the fact that the income no longer spent for imported fossil heating fuels is used by households to expand their consumption of other goods and services.

Our results are roughly in line with the estimates made by Ecoplan/Sigmaplan (2007), but differ from the study published recently by Roson and Sartori (2016). The latter use damage functions and a CGE model to estimate for 140 countries and six specific damages (sea level rise, agricultural productivity, human health, tourism flow and household's energy demand) the change in GDP for a temperature increase of $3{ }^{\circ} \mathrm{C}$. They find for Switzerland a positive impact on GDP equal to $1.42 \%$, mainly driven by an increase in tourism attractiveness. However, their estimates do not include the excess mortality, which represents in our analysis the most important cost of climate change. The differences in results between the studies also indicate that the thorough use of available local information at national and sub-national scales is important when we try to quantify and monetize climate change impacts.

Uncertainties about the overall impacts of CC are still enormous. Especially, the full consequences of future extreme weather events remain unknown. Despite the estimates presented in this paper, we still know too little about the repercussions of global consequences of $\mathrm{CC}$ on Switzerland. The monetization of nonmarket goods, such as biodiversity or scenic beauty, is another very challenging 
issue. Obvious limitations of our study include an incomplete set of simulated impacts, an overly simple relationship between high temperatures and labour productivity, and linear scaling of results from studies that use different (but similar) climate scenarios.

\section{References}

David Abler, Karen Fisher-Vanden, Marc McDill, Richard Ready, James Shortle, and Ian Sue Wing. Economic Impacts of Projected Climate Change in Pennsylvania. Report to the Department of Environmental Protection, 2009.

B. Aebischer, G. Catenazzi, G. Henderson, and M. Jakob. Impact of climate change on thermal comfort, heating and cooling energy demand in Europe. In Saving energy - just do it! European Council for an Energy Efficient Economy ECEEE, 2007.

P.S. Armington. A Theory of Demand for Products Distinguished by Place of Production. IMF Staff Papers, 16:159-78, 1969.

Frédéric Babonneau, Philippe Thalmann, and Marc Vielle. Defining deep decarbonization pathways for Switzerland: an economic evaluation. Climate Policy, 18(1):1-13, 2018.

Badri Narayanan, Angel Aguiar, and Robert McDougall, editors. Global Trade, Assistance, and Production: The GTAP 8 Data Base. Center for Global Trade Analysis, Purdue University, 2012.

Bergwelten 21 and GRF Davos. Klimawandel Graubünden, Arbeitspapier 3: Risiken und Chancen. Chur, November 2015.

M. Berrittella, A. Bigano, R. Roson, and R. S.J. Tol. A general equilibrium analysis of climate change impacts on tourism. Tourism Management, 27(5):913924, October 2006.

F. Bosello, R. Eboli, and R. Pierferedici. Assessing the Economic Impacts of Climate Change. An Updated CGE Point of View. Nota Di Lavoro, Fondazione Eni Enrico Mattei, January 2012.

Marshall Burke, Solomon M. Hsiang, and Edward Miguel. Global non-linear effect of temperature on economic production:. Nature, 527:235-239, 2015. 
CH2011. Swiss climate change scenarios CH2011. Technical report, C2SM, MeteoSwiss, ETH, NCCR Climate, and OcCC, 2011.

CH2014-Impacts. Toward Quantitative Scenarios of Climate Change Impacts in Switzerland. OCCR, FOEN, MeteoSwiss, C2SM, Agroscope and ProClim., 2014.

Jean Château, Rob Dellink, and Elisa Lanzi. An Overview of the OECD ENVLinkages Model. OECD Environment Working Papers, (65), 2014.

Y.-H. Henry Chen, Sergey Paltsev, John Reilly, Jennifer Morris, Valerie Karplus, Angelo Gurgel, Niven Winchester, Paul Kishimoto, Elodie Blanc, and Mustafa Babiker. The MIT Economic Projection and Policy Analysis (EPPA) Model: Version 5. Technical Report 16, Joint Program Technical Note Series, 2017.

M. Christenson, H. Manz, and D. Gyalistras. Climate warming impact on degreedays and building energy demand in Switzerland. Energy Conversion and Management, 47:671-686, 2006.

Juan-Carlos Ciscar, László Szabó, Denise van Regemorter, and Antonio Soria. The integration of PESETA sectoral economic impacts into the GEM-E3 Europe model: methodology and results. Climatic Change, 112(1):1-6, 2012.

Hélia Costa, Graham Floater, Hans Hooyberghs, Stijn Verbeke, and Koen De Ridder. Climate change, heat stress and labour productivity: A cost methodology for city economies. Centre for Climate Change Economics Policy Working Paper No. 278 and Grantham Research Institute on Climate Change and the Environment, Working Paper No. 248, 2016.

Daniela D'Ippoliti, Paola Michelozzi, Claudia Marino, Francesca de'Donato, Bettina Menne, Klea Katsouyanni, Ursula Kirchmayer, Antonis Analitis, Mercedes Medina-Ramón, Anna Paldy, Richard Atkinson, Sari Kovats, Luigi Bisanti, Alexandra Schneider, Agnès Lefranc, Carmen Iñiguez, and Carlo A. Perucci. The impact of heat waves on mortality in 9 european cities: results from the euroHEAT project. Environmental Health, 9(1):37, Jul 2010. ISSN 1476-069X.

P. Dowling. The Impact of Climate Change on the European Energy System. Energy Policy, 60:406-417, 2013.

Ding Du, Xiaobing Zhao, and Ruihong Huang. The impact of climate change on developed economies. Economics Letters, 153:43-46, 2017. 
Ecoplan. Empfehlungen zur Festlegung der Zahlungsbereitschaft für die Verminderung des Unfall- und Gesundheitsrisikos (value of statistical life). Technical report, Swiss Federal Office for Spatial Developmentand Swiss Council for Accident Prevention, Bern, 2016.

Ecoplan/Sigmaplan. Auswirkungen der Klimaänderung auf die Schweizer Volkswirtschaft (nationale Einflüsse). Technical report, Swiss Federal Office for the Environment and Swiss Federal Office of Energy, Bern, 2007.

Ernst Basler and Partner/CSD Ingenieurs. Risiken und Chancen des Klimawandels im Kanton Freiburg, 2015.

Ernst Basler + Partner, Eidg. Forschungsanstalt WSL, and WSL-Institut für Schnee und Lawinenforschung SLF. Risiken und chancen des klimawandels im kanton aargau. Commissioned by Federal Office for the Environment (FOEN), Bern, 2013.

A.K. Faust, C. Gonseth, and M. Vielle. The economic impact of climate-driven changes in water availability in switzerland. Water Policy, 17(5):848-864, 2015.

FSO. Tourism satellite account 2015. Swiss Federal Statistical Office, Neuchâtel, 2015.

J. Fuhrer and P. Calanca. Bewässerungsbedarf und Wasserdargebot unter Klimawandel, eine regionale Defizitanalyse. Agrarforschung Schweiz, 5(6):256$263,2014$.

C. Gonseth and M. Vielle. The general equilibrium impacts of climate change for the Swiss ski industry. Submitted to Environmental Modeling and Assessment, 2017.

C. Gonseth, P. Thalmann, and M. Vielle. Impacts of global warming on energy use for heating and cooling with full rebound effects in Switzerland. Swiss Journal of Economics and Statistics, 153(4):341-369, 2017.

J. M. Hamilton, D. J. Maddison, and R. S.J. Tol. Climate change and international tourism: A simulation study. Global Environmental Change, 15(3):253-266, October 2005. 
Geoffrey Heal and Jisung Park. Reflections - Temperature Stress and the Direct Impact of Climate Change: A Review of an Emerging Literature. Review of Environmental Economics and Policy, 10(2):347-362, 2016.

Paul D Henne, Moritz Bigalke, Ulf Büntgen, Daniele Colombaroli, Marco Conedera, Urs Feller, David Frank, Jürg Fuhrer, Martin Grosjean, Oliver Heiri, et al. An empirical perspective for understanding climate change impacts in switzerland. Regional environmental change, pages 1-17, 2018.

A Holzkämper, P Calanca, M Honti, and J Fuhrer. Projecting climate change impacts on grain maize based on three different crop model approaches. Agricultural and forest meteorology, 214:219-230, 2015.

Trevor Houser, Solomon Hsiang, Robert Kopp, Kate Larsen, Michael Delgado, Amir Jina, Michael Mastrandrea, Shashank Mohan, Robert Muir-Wood, D. J. Rasmussen, James Rising, Paul Wilson, Karen Fisher-Vanden, Michael Greenstone, Geoffrey Heal, Michael Oppenheimer, Nicholas Stern, Bob Ward, Michael R. Bloomberg, Henry M. Paulson, and Thomas F. Steyer. Economic Risks of Climate Change: An American Prospectus. Columbia University Press, 2015.

IFEC, Bergwelten 21, InnovaBridge, Consavis, and RIBO architecture. Analyse klimabedingter Risiken und Chancen in der Schweiz, Fallstudie Kanton Tessin, 2016.

INFRAS and Egli Engineering. Klimabedingte risiken und chancen 2060. regionale fallstudie kanton basel-stadt. Entwurf Schlussbericht zur Kommentierung durch Fachstellen, Zürich, 2014a.

INFRAS and Egli Engineering. Klimabedingte risiken und chancen 2060. regionale fallstudie kanton uri. Zürich, 2014b.

INFRAS, Ecologic \& Rütter, and Partner. Auswirkungen der Klimaänderung auf die Schweizer Volkswirtschaft (internationale Einflüsse), Commissioned by Federal Office for the Environment, 2007.

INFRAS, Egli Engineering, Sofies, and INDDIGO. Analyse des risques et opportunités liés aux changements climatiques en Suisse, Etude de cas Canton Genève et Grand-Genève. Genève, 2015.

International Energy Agency. World Energy Outlook. OECD/IEA, 2015. 
IPCC. Summary for Policymakers. In: Climate Change 2013: The Physical Science Basis. Contribution of Working Group I to the Fifth Assessment Report of the Intergovernmental Panel on Climate Change. Cambridge, UK and New York, USA, 2013.

Dale W. Jorgenson, Richard J. Goettle, Brian H. Hurd, Joel B. Smith, and David M. Mills. U.S. market consequences of global climate change. Pew Center on Global Climate Change, 2004.

A. Kemmler, A. Piégsa, P. Wüthrich, M. Keller, M. Jakob, and G. Catenazzi. Analyse des schweizerischen Energieverbrauchs 2000-2014 nach Verwendungszwecken, Commissioned by the Swiss Federal Office of Energy, 2015.

A. Kirchner, A. Kemmler, P. Hofer, M. Keller, M. Jakob, and G. Catenazzi. Analyse des schweizerischen Energieverbrauchs 2000-2009 nach Verwendungszwecken. Technical report, Bundesamt für Energie BFE, 2010.

N. Köplin, B. Schädler, D. Viviroli, and R. Weingartner. Relating climate change signals and physio-graphic catchment properties to clustered hydrological response types. Hydrology and Earth System Sciences, 16(7):2267-2283, 2012.

James C. Liljegren, Richard A. Carhart, Philip Lawday, Stephen Tschopp, and Robert Sharp. Modeling the Wet Bulb Globe Temperature Using Standard Meteorological Measurements. Journal of Occupational and Environmental Hygiene, 5(10):645-655, 2008.

C. Matasci. The vulnerability of Switzerland towards climate change: the case of tourism. In Belpasso International Summer School, 2010.

R. Meier. Sozioökonomische Aspekte von Klimaänderungen und Naturkatastrophen in der Schweiz. Technical report, vdf Hochschulverlag, ETH Zürich, Zürich, 1998.

C. Nathani, D. Sutter, R. van Nieuwkoop, M. Peter, S. Kraner, M. Holzhey, H. Rütter, and R. Zandonella. Energy related disaggregation of the Swiss InputOutput Table. Technical report, SFOE, EWG Publication, Bern, 2011.

G. C. Nelson, D. van der Mensbrugghe, H. Ahammad, E. Blanc, K. Calvin, T. Hasegawa, P. Havlik, E. Heyhoe, P. Kyle, H. Lotze-Campen, M. von Lampe, D. Mason d'Croz, H. van Meijl, C. Müller, J. Reilly, R. Robertson, R. D. Sands, 
C. Schmitz, A. Tabeau, K. Takahashi, H. Valin, and D. Willenbockel. Agriculture and climate change in global scenarios: why don't the models agree. Agricultural Economics, 45(1):85-101, 2014.

OcCC and ProClim. Climate change and Switzerland 2050: Expected impacts on environment, society and economy. Technical report, Organe consultatif sur les changements climatiques, Berne, 2007.

OECD. Mortality risk valuation in environment, health and transport policies. 2012.

OECD. The economic consequences of climate change. 2015.

D. Paci. Human Health Impacts of Climate Change in Europe. Report for the Peseta II project, 2014.

M. Perroud and S. Bader. Klimaänderung in der Schweiz. Indikatoren zu Ursachen Auswirkungen, Massnahmen. Umwelt-Zustand Nr. 1308. Bundesamt für Umwelt, Bern, und Bundesamt für Meteorologie und Klimatologie, Zürich, 86 S., 2013.

C. Rosenzweig, J. Elliott, D. Deryng, A. C. Ruane, C. Müller, A. Arneth, K. J. Boote, C. Folberth, M. Glotter, N. Khabarov, K. Neumann, F. Piontek, T. A. M. Pugh, E. Schmid, E. Stehfest, H. Yang, and J. W. Jones. Assessing agricultural risks of climate change in the 21st century in a global gridded crop model intercomparison. Proceedings of the National Academy of Sciences, 111(9): 3268-3273, 2014.

R. Roson and M. Sartori. Estimation of Climate Change Damage Functions for 140 Regions in the GTAP 9 Database. Journal of Global Economic Analysis, 1 (2):78-115, 2016.

Olli Seppänen, William J Fisk, and Quanhong Lei-Gomez. Effect of temperature on task performance in office environment. Ernest Orlando Lawrence Berkeley National Laboratory, LBNL-60946, Berkeley, 2006.

Swiss Confederation. Adaptation to Climate Change in Switzerland - goals, challenges and areas of action. Part 1 of the Federal Council's strategy of 2 March 2012. Federal Office for the Environment (FOEN), Bern., 2012. 
Richard S. J. Tol. The economic Impacts of Climate Change. Review of Environmental Economics and Policy, 12(1):4-25, 2018.

Paul van der Linden and J Mitchell, editors. ENSEMBLES: Climate Change and its Impacts: Summary of research and results from the ENSEMBLES project. Met Office Hadley Centre, 2009.

Rolf Weingartner, Massimiliano Zappa, Donat Job, Sonja Angehrn, Eivind Helland, Daniel Rietmann, Robert Schneider, Christian Duprazand Christian Mueller, Nina Boogen, Daniel Spreng, Florian Widmer, Pascal Hänggi, Wilfried Haeberli, Andreas Linsbauer, Frank Paul, Thomas Bosshard, Tracy Ewen, Sven Kotlarski, Christoph Schär, Andreas Fankhauser, Florian Bobierska, Tobias Jonas, Andreas Bauder, Daniel Farinotti, Stephanie Usselmann, Alexander Beer, Thierry Glassey, Andreas Ludwig, Valentin Métraux, Mina Ossiaa, Mélanie Raymond Pralong, Dieter Rickenmann, Manfred Stähli, and Jens M. Turowski. Auswirkungen der Klimaänderung auf die Wasserkraftnutzung Synthesebericht. Beiträge zur Hydrologie der Schweiz, (38), 2011.

K. Wiebe, H. Lotze-Campen, R. Sands, A. Tabeau, D. van der Mensbrugghe, A. Biewald, B. Bodirsky, S. Islam, A. Kavallari, D. Mason-D'Croz, C. Müller, A. Popp, R. Robertson, S. Robinson, H. van Meijl, and D. Willenbockel. Climate change impacts on agriculture in 2050 under a range of plausible socioeconomic and emissions scenarios. Environmental Research Letters, 10(8): 085010, 2015.

Xiaobing Zhao, Mason Gerety, and Nicolai V. Kuminoff. Revisiting the temperature-economic growth relationship using global subnational data. Journal of Environmental Management, 223:537-544, 2018.

\section{Acknowledgements}

The research leading to these results has received funding from the Swiss Federal Office for the Environment. We would like to thank Roland Hohmann, Sabine Kleppek, Pamela Köllner-Heck, Roger Ramer and an anonymous reviewer for their helpful comments and suggestions.

The assessment presented in this paper would not have been possible without the help of several researchers who kindly provided additional information/data from their original papers. Their helps were much appreciated: Paul Dowling 
who gave the impact of CC on Austrian electricity price. Gerald C. Nelson and Keith Wiebe who provided the detailed results on the impacts of $\mathrm{CC}$ on agriculture prices published respectively in Nelson et al. (2014) and in Wiebe et al. (2015). The authors of the Hamburg Tourism Model and in particular Richard Tol who permitted us to use their model for our simulations. Nans Addor who extracted changes for mean annual, summer and winter discharges at catchments level. Ole Rössler for his help on hydrological issues.

The ENSEMBLES data used in this work was funded by the EU FP6 Integrated Project ENSEMBLES (Contract number 505539) whose support is gratefully acknowledged.

Sole responsibility for the content of this paper lies with the authors. 


\section{Appendix A. Industrial classification}

The GEMINI-E3 model was initially designed to assess climate and energy policies aiming at reducing $\mathrm{CO}_{2}$ emissions. Then, the model was extended to the analysis of the economic impacts of $\mathrm{CC}$. Therefore the disaggregation of sectors was chosen according to these two purposes. First, we disaggregate the energy supply/demand into 6 sectors/goods: coal, crude oil, natural gas, petroleum products, electricity and district heating. Transportation was represented through three sectors: land, sea and air transports. Then, we define the sectoral structure of the model in order to assess the economic impact of CC hazards on particularly vulnerable sectors at the Swiss national level, such as tourism, agriculture, human health, insurance and water distribution. For agriculture, the model describes four agricultural activities (i.e. grains and oil seeds, livestock, forestry and other crops.) according to their contributions to Swiss agriculture production and their vulnerabilities to $\mathrm{CC}$. The tourism sector includes all activities (accommodation, transport, retail sector, etc) that are linked to tourism. Tourism is disaggregated into three segments, winter overnight tourism, one-day winter tourism and other forms of tourism.

\begin{aligned} & Table A.1: Industrial classification \\ & \hline 1 Coal \\ & 2 Crude oil \\ & 3 Natural gas \\ & 4 Petroleum products \\ & 5 Electricity \\ & 6 District heating \\ & 7 Grains and oil seeds \\ & 8 Other crops \\ & 9 Livestock \\ & 10 Forestry \\ & 11 Industry \\ & 12 Land transport \\ & 13 Water transport \\ & 14 Air transport \\ & 15 Insurance \\ & 16 Health \\ & 17 Other services \\ & 18 Winter overnight tourism \\ & 19 One-day winter tourism \\ & 20 Other forms of tourism \\ & 21 Drinking water \\ & \hline\end{aligned}




\section{Appendix B. Production structure of agricultural sectors in GEMINI-E3}

In GEMINI-E3, the production structure distinguishes water as an input and allows sectors to choose between employing drinking water and extracting water themselves. In the agricultural sector, land is combined with irrigation to form an irrigation-land aggregate. The model distinguishes between raw water for irrigation and raw water for other uses. Raw water for irrigation corresponds to water mainly used from the beginning of spring to the beginning of autumn, which corresponds to the main growing season of the plants. These factors are mobile between sectors, but modeled as distinct goods, so raw irrigation water cannot be taken for any other use and vice versa. More details can be found in Faust et al. (2015).

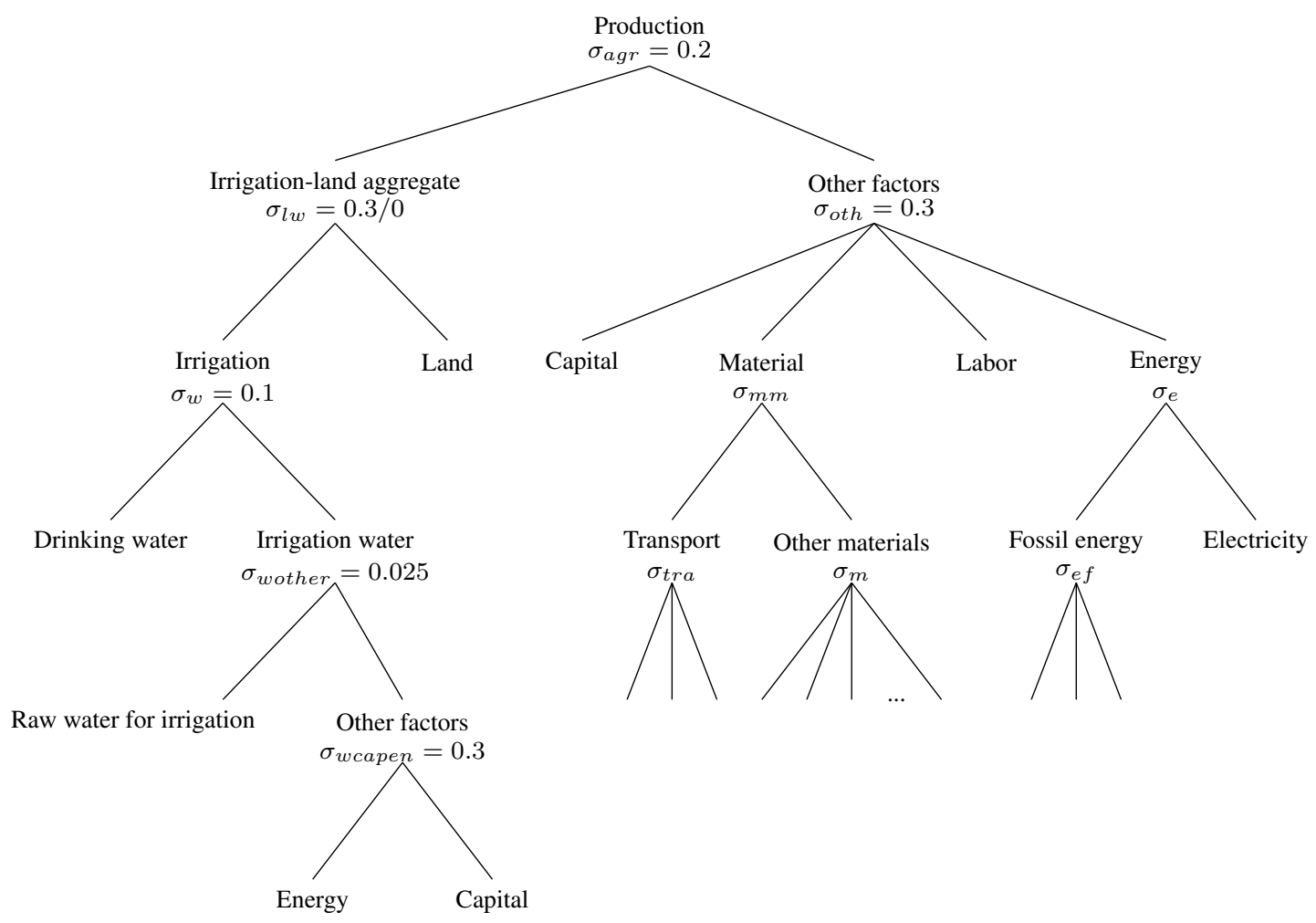

Figure B.1: Nested CES production function used for agricultural sector 


\section{Appendix C. Production structure of winter tourism in GEMINI-E3}

The production structure of the winter tourism sectors is shown in Figure C.2. A natural snow resource has been introduced into the model. The chosen structure assumes that winter tourism sectors can respond to a reduction in natural snow availability by producing more artificial snow. This artificial snow requires a mix of capital, electricity, labor and water inputs. More details can be found in Gonseth and Vielle (2017).

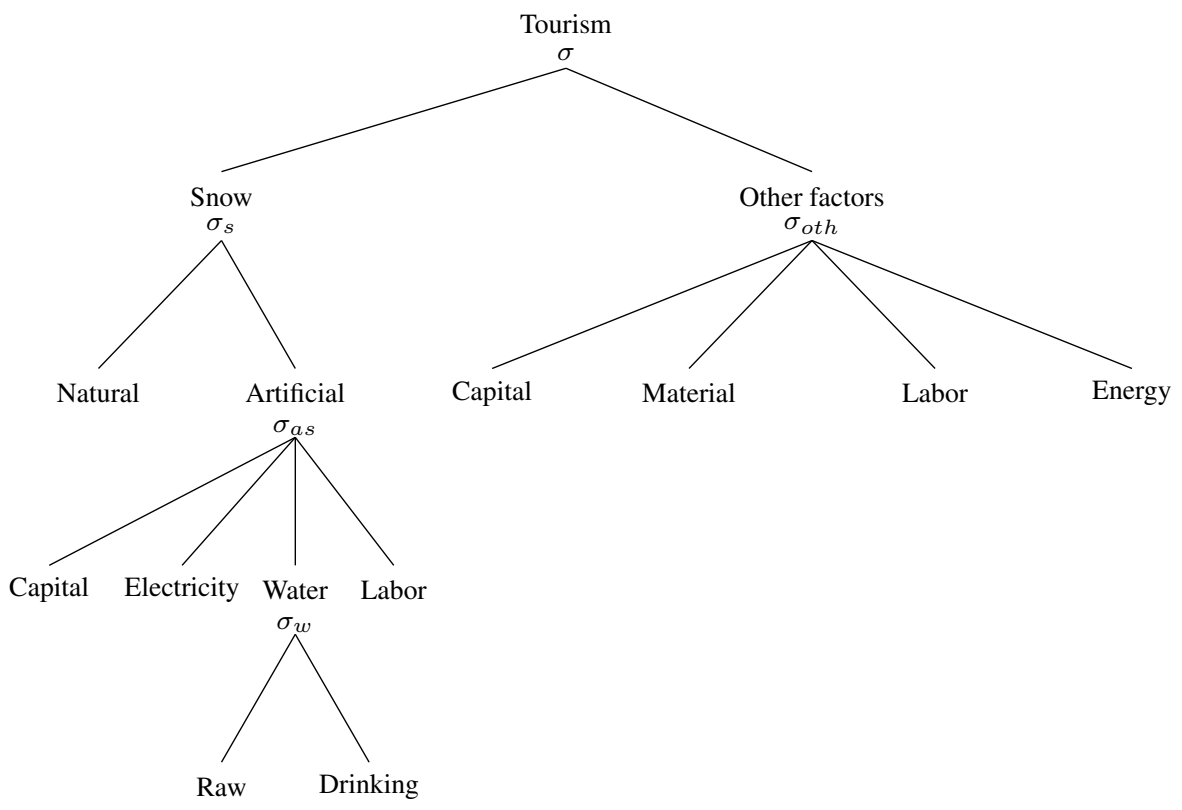

Figure C.2: Nested CES production function used for the winter tourism 